\title{
Una hacienda zacatecana durante el porfiriato
}

\author{
Víctor Manuel González Esparza
}

\section{Introducción}

Según Luis Cabrera, Andrés Molina Enriquez fue para la revolución agraria lo que José Ma. Luis Mora para la Reforma. ${ }^{1}$ El símil es acertado. Molina Enriquez, recuperando una tradición política iberoamericana, fundamentó al igual que Mora la existencia del actual Estado mexicano. ${ }^{2}$ Sin embargo, la importancia del primero continúa estando en su análisis de la propiedad (semejante en esto a Mariano Otero); más aún, rebasando con ello a Wistano Luis Orozco, Molina Enríquez integró el estudio de la propiedad a uno de los grandes y recurrentes problemas del país: la insuficiencia de cereales para la alimentación de la población mayoritaria (en términos actuales, con la falta de autosuficiencia alimentaria). De hecho, la pregunta inicial de Molina Enríquez fue el porqué México importaba cereales; su respuesta fue un libro indispensable, Los Grandes Problemas Nacionales: problemas derivados precisamente de la expansión de los latifundios en las regiones productoras de cereales, "la zona fundamental de sustentación o zona de los cereales".

Molina Enríquez ciertamente afirmó que los grandes latifundios eran una amortización donde predominaba, citando a Jovellanos, "la vanidad y el orgullo". Sin embargo, su otra afirmación discutida de que la hacienda no era un negocio me parece que ha sido malinterpretada. No era un negocio que posibilitara el "progreso" del país. La "economía de miseria" de las haciendas, nula reinversión y bajos salarios, si bien proporcionaba una renta segura al propietario, impedía el desarrollo regional y nacional. Retornar a los clásicos. Este ensayo, a partir de un caso concreto, pretende retomar la perspectiva crítica de Molina Enríquez sobre la hacienda porfirista. ${ }^{3}$

La hacienda de Mezquite durante el porfiriato, situada cerca de Fresnillo en las tierras semiáridas de Zacatecas, se estudia por medio de su contabilidad. El análisis de los inventarios mostró su utilidad desde Jan Bazant. Sin embargo, hasta donde conozco, no se han trabajado series de inventarios que abarquen toda una época. Quizá el hallazgo de este ensayo sea el haber reunido 25 inventarios de una hacienda zacatecana durante el régimen de Porfirio Díaz.

\footnotetext{
1 Moisés González Navarro, Sociologia e Historia de México, México, El Colegio de México (Col. Jornadas núm. 67), 1a. reimp., 1985, 49 p.

${ }^{2}$ Andrés Molina Enríquez, Los grandes problemas nacionales, Prólogo de Arnaldo Córdova, México, ERA, 3a. ed., 1981, 523 p. El prólogo de A. Córdova acentúa precisamente la concepción política de Molina Enríquez.

${ }^{3}$ Perspectiva semejante por cierto a la de W. Kula en: "Una economía agricola sin acumulación: Polonia en los siglos XVI-XVIII", Agricultura y desarrollo del capitalismo, Madrid, Alberto Corazón Ed., 1974, p. 343-379.
} 
Pero el uso de los inventarios tiene sus limitaciones. Una fundamental: no informan sobre la relación de la hacienda con los mercados. Sólo puedo decir que espero cubrir este aspecto en otro momento, desde luego con otras fuentes. La fuente más importante para este trabajo fue el Fondo Rul y Azcárate del Archivo General de la Nación. La importancia para la historia del país de este Fondo se ha difundido poco.

Escribir sobre la rentabilidad de una hacienda sin considerar las relaciones de trabajo seria hacerlo de una manera incompleta. Por ello he incluido un apartado especial para los salarios, jornales y deudas de los trabajadores de Mezquite.

He anticipado mi conclusión citando a Molina Enriquez. No puedo ni quiero generalizarla para todas las haciendas del país. Sin embargo, los estudios monográficos sin perspectiva global aumentan la información pero no mejoran el conocimiento sobre las haciendas. El otro peligro es repetir generalidades. Queda para el lector el juicio sumario.

\section{Origen y evolución del latifundio}

Entre las causas de la revolución mexicana de 1910 es ineludible mencionar el proceso acelerado de concentración de la propiedad territorial, y dentro de las causas de este proceso, a su vez, el deslinde de baldíos, o como se.le calificó certeramente, "el derroche de baldios". ${ }^{4}$ Las leyes de colonización y deslinde $(1863,1883$ y 1894) posibilitaron una de las más grandes transferencias de tierras de la historia del país, sólo comparable a la conquista española, a la nacionalización de los bienes eclesiásticos y a la reforma agraria. Moisés González Navarro ha calculado que se otorgaron 43309 títulos de baldíos entre 1867 y 1911 , los cuales correspondieron a 40198377 hectáreas, en su mayoría en el norte y sur del país y durante el porfiriato. ${ }^{5}$ El derroche de baldios no sólo afectó a las comunidades agrícolas, sino también a los hacendados de viejo cuño, a los que Molina Enriquez caracterizó como "criollos señores o viejos" y que llamó "gente decente". Un observador escribió al respecto: "el monopolio territorial al que se enfrentó la revolución no era el antiguo colonial, sino el creado por el despojo que los deslindadores hicieron de los antiguos hacendados con el pretexto de los baldíos". ${ }^{6}$ Exageraba; sin embargo, registra un conflicto clave entre viejos y nuevos terratenientes. Precisamente por ese conflicto se puede conocer el origen y la evolución de los títulos de propiedad de Mezquite, hacienda objeto de este estudio.

\footnotetext{
4 Moisés González Navarro. "El Porfiriato. La vida social", en Historia Moderna de México, t. IV, 4a. ed., México-Buenos Aires, Ed. Hermes, 1985, p. 187.

s Ibid., V. M. González Navarro, "Tenencia de la Tierra y población agrícola (18771960)" Historia Mexicana, vol. XIX: I, (73), jul.-sep. 1969, p. 62-86.

- El observador es Lorenzo Cossio, citado por M. González Navarro en "El Porfiriato...", op. cit., p. 198-199.
} 


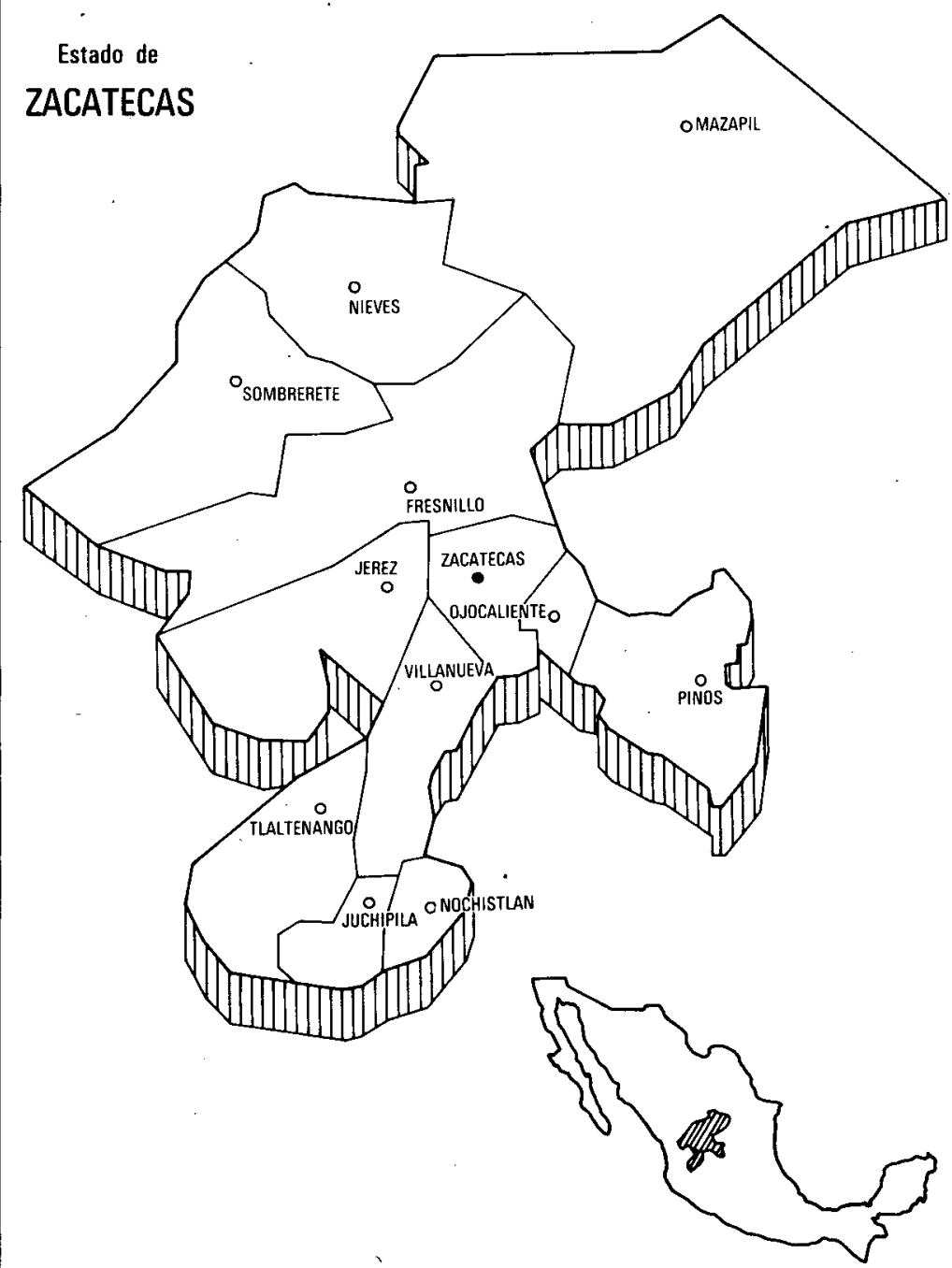

Fuente

Geografía y Estadística de Zacatecas

Secrecaría de Fomento, 1894

Elías Amador, Noticia Estadística de Zacatecas.

Zacatecas, Tip. de la Escuela de Artes y Oficios, 1982 
El 14 de agosto de 1885, la compañía Calderón y Herrera obtuvo la concesión para deslindar baldíos en el estado de Zacatecas. Por medio de su gerente, José Valenzuela, de su apoderado jurídico, licenciado Wistano Luis Orozco (si, el mismo que escribió sobre la cuestión agraria) y del ingeniero Francisco P. Beltrán, la compañía realizó (ca. 1887) el deslinde de la hacienda de Mezquite propiedad de Miguel Rul y Azcárate. ${ }^{7}$ Pero antes de tratar especificamente este deslinde, no deja de ser atractivo revisar la historia de los títulos del latifundio.

Diego de Ibarra, fundador de Zacatecas entre otros, gracias a mercedes reales formó uno de los más grandes latifundios en Zacatecas, con cabecera en Trujillo, cerca de Fresnillo, el cual junto con otras propiedades tanto rústicas como mineras, vinculó al mayorazgo de Salinas en 1578. "Este mayorazgo fue uno de los pocos creados en los siglos XVI y XVII por los mineros y habitantes de Zacatecas."8 El Mayorazgo lo heredó Mariana Ibarra de Velasco, Marquesa de Salinas; sin embargo, en 1611 obtuvo licencia real para vender las haciendas de Trujillo y Valparaiso, en las cuales había fincado el mayorazgo de su título, pues residía en España.

Cabe hacer una observación sobre el origen del latifundio al que perteneció Mezquite. Según una hipótesis planteada por George McCutchen McBride en 1923, la encomienda facilitó la adquisición de tierras ${ }^{9}$ y por lo tanto la formación de los latifundios. La hipótesis es válida para el valle de México, como lo mostró Gibson, pero no para todo el país. Las haciendas ganaderas del norte del país, por ejemplo, no tuvieron antecedentes de encomienda por la simple y sencilla razón de que se fundaron donde había pocos indios dominados (la "guerra chichimeca" los aniquiló). ${ }^{10} \mathrm{McBride}$, por cierto, reconoce que muchas haciendas de México tuvieron su origen en las extensas donaciones de tierras hechas por la Corona española a los conquistadores, aunque lanza también una afirmación ahora muy discutible cuando dice que "a menudo han permanecido (las tierras donadas por la Corona) en posesión de la misma familia". ${ }^{11}$ Sin embargo, por lo dicho anteriormente, el latifundio inicial de Mezquite no tuvo su origen en una encomienda sino en las mercedes reales, debido, es lógico suponer, a la falta de mano de obra indígena; tampoco perteneció a la misma familia, como lo muestra el cuadro 1.

Así pues, la hacienda de Mezquite tuvo por lo menos siete familias propietarias, incluyendo la Pérez Gálvez y Rul. Si se atiende la discusión sobre la continuidad de la tenencia de la tierra, puede decirse que el siglo XVII fue el del origen del latifundio de Mezquite, constituido por mercedes reales y vinculado a un Mayorazgo. El siglo XVII fue el de la inestabilidad (cinco familias propietarias), debido sobre todo a las dificultades económicas (deudas) de sus propietarios. Para el siglo XVIII, en cambio, Mezquite sólo tuvo dos familias propietarias.

7 Archivo General de la Nación. Fondo Rul y Azcárate (en las citas siguientes AGNFRyA), Caja 341.

${ }^{8}$ Ibid.

9 George McCutchen McBride, "Los sistemas de propiedad rural en México", Problemas Agrícolas e Industriales de México, vol. 3, núm. 3, julio-sep. de 1951, p. 39.

10 Magnus Mörner, "La hacienda hispanoamericana: examen de las investigaciones y debates recientes" Haciendas, Latifundios y Plantaciones en América Latina, 2a. ed. México, Siglo XXI-CLACSO, 1978, p. 15-48. El trabajo continúa siendo una excelente guía para la investigación.

$"$ G. M. McBride, op. cit., p. 36. 


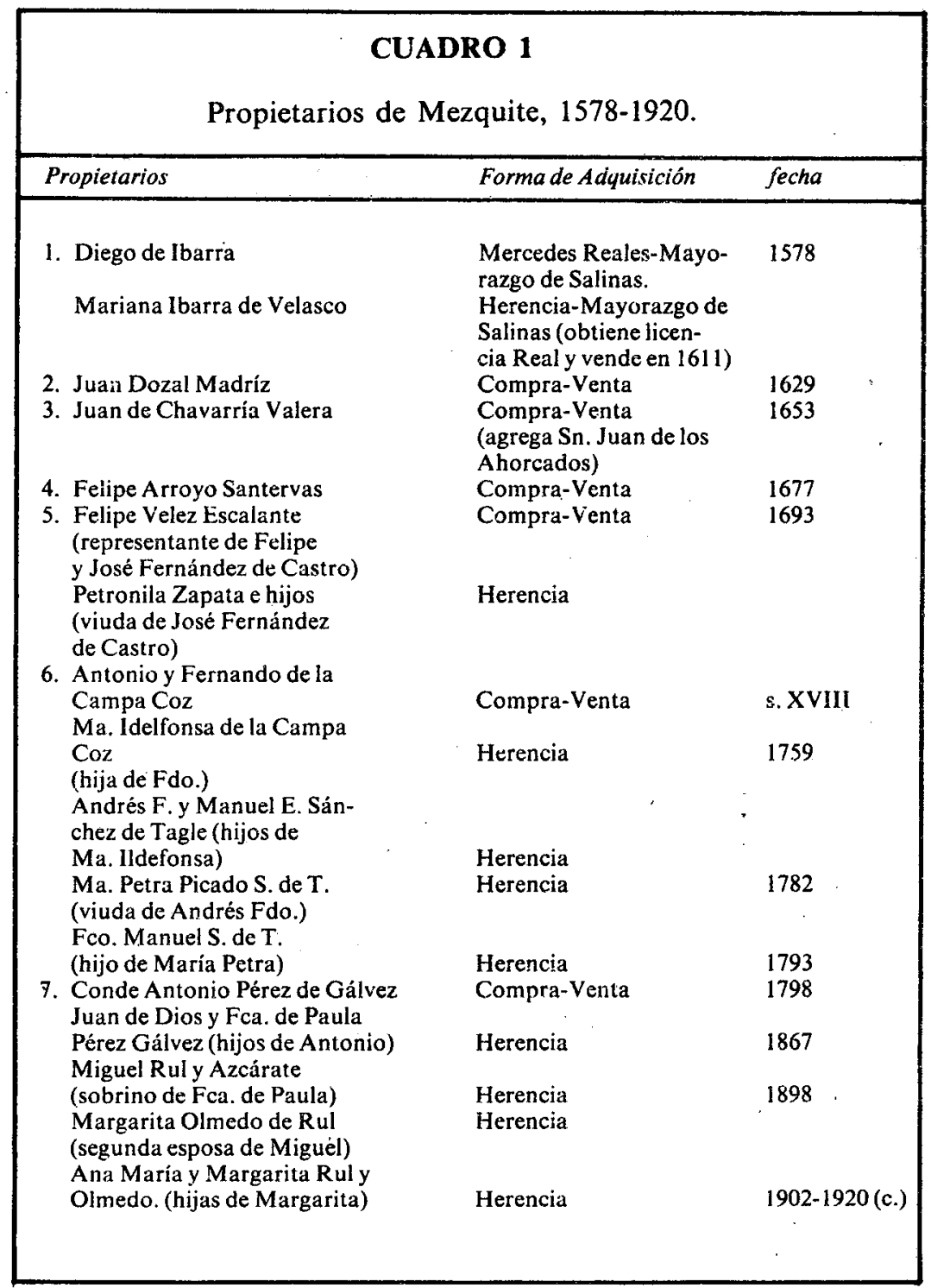

Fuente: AGN, FRA, Cajas 337 y 341 .

Finalmente, el siglo XIX (a partir de 1798 hasta el periodo revolucionario del siglo XX) significó para el latifundio de Mezquite la época de la estabilidad, de la continuidad de una misma familia propietaria. En esta perspectiva de largo plazo, considerando sólo los títulos de la propiedad; el siglo XIX fue para Mezquite no sólo el de continuidad sino también el de crecimiento.

Los primeros datos de la superficie de Mezquite fueron levantados a partir de la Cédula de Composición (octubre de 1754) y cạlculados el año de 1758: 275 sitios de ganado mayor, aproximadamente 484000 hectáreas, incluyendo las tierras de Pozohondo (véase el mapa de Mes- 


\begin{tabular}{|c|c|c|c|}
\hline \multicolumn{4}{|c|}{$\begin{array}{c}\text { CUADRO } 2 \\
\text { Superficie de Mezquite y anexas, } 1881\end{array}$} \\
\hline & $\begin{array}{c}\text { Sitio de } \\
\text { Ganado Mayor }\end{array}$ & Caballerias & Hectareas' \\
\hline Mezquite & 57 & 33 & 101486 \\
\hline Salada & 17 & 23 & 30835 \\
\hline Norias & 74 & 3 & 230059 \\
\hline $\begin{array}{l}\text { Estancias (Colorada, } \\
\text { Ahorcados y Gato) }\end{array}$ & 90 & 16 & 158705 \\
\hline Total & 239 & 34 & 421087 \\
\hline
\end{tabular}

Nota 1: Los cálculos en hectáreas se deben a la propia hacienda; yo he tomado como equivalente 1760 hectáreas por sitio de ganado mayor.

quite y Zacatecas). ${ }^{12}$ En 1770 se divide el latifundio quedando sólo para Mezquite 160 sitios de ganado mayor (cerca de 281600 hectáreas); en 1803 se le agregan 6 sitios. ${ }^{13}$ Para 1881 la superficie total de Mezquite y anexas (superficie no integrada; véase nuevamente el mapa) era ya de 239 sitios de ganado mayor con 34 caballerias. ${ }^{14}$ La diferencia con el año de 1803 se debe a la hacienda de Norias (cerca de 74 sitios), incorporada al latifundio a mediados del siglo XIX (cuadro 2).

Resulta paradójico el crecimiento y la estabilidad de Mezquite en un siglo especialmente conflictivo, ${ }^{15}$ como también la desintegración de algunas haciendas en ciertos estados de la república a fines del siglo XIX, frente a la hipótesis del acaparamiento de tierras. ${ }^{16}$

12 AGN-FRyA, Caja 341. Al parecer, la rectificación de las medidas a 275 sitios de ganado mayor no prosperó, pues en años posteriores se consideraron sólo 254 sitios como medida titular.

13 AGN-FRyA, Caja 337.

14 AGN-FryA, Caja 341. Los datos son para el 22 de febrero de 1881.

is Mezquite sobrevivió a pesar de que Francisca de Paula Pérez Gálvez, tía de Miguel Rul, apoyó la intervención francesa. Juárez ciertamente expropió a Francisca una hacienda en Nuevo León; sin embargo, los Pérez Gálvez contaban con 12 haciendas de campo y 6 de beneficio ubicadas, además de en Zacatecas, en San Luis Potosi, Nuevo León, Guanajuato, etc., 6 casas en la ciudad de México, etc., con un capital aproximado de 10 millones de pesos a mediados del siglo XIX, AGN-FRyA, Caja 87.

16 Jan Bazant documentó algunos casos de desmoronamiento de la gran propiedad en: Los bienes de la Iglesia en México (1856-1876): aspectos económicos y sociales de la Revolución Liberal, México, El Colegio de México, 2a. ed., 1977. De obligada consulta: Cinco haciendas mexicanas. Tres siglos de vida rural en San Luis Potosí, (1600-1910), México, El Colegio de México, 2a. ed., 1980, 229. p. Jesús Gómez Serrano ha mostrado abundantemente la desintegración de las haciendas en Aguascalientes, previa a la revolución: $E I$ Mayorazgo Rincón Gallardo. Disolución del vínculo y reparto de las haciendas, México, Centro de Investigaciones regionales de Aguascalientes, 1984, 156 p. Es también indispensable el libro de Beatriz Rojas: La destrucción de la hacienda en Aguascalientes, 19101931, México, El Colegio de Michoacán, 1981, $159 \mathrm{p}$. 


\section{HACIENDA MEZQUITE}
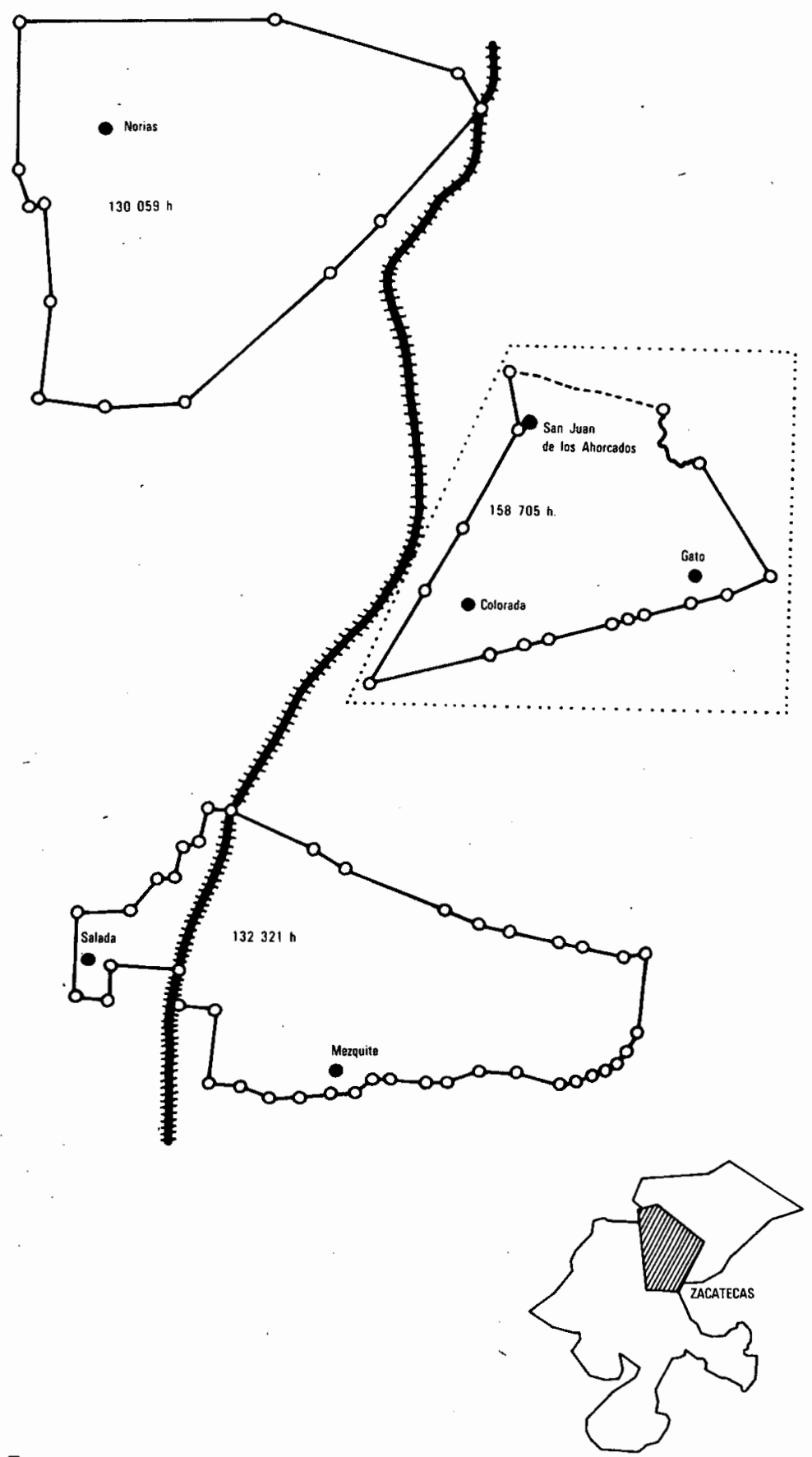

Fuente

Mapoteca del Servicio Meteorológico Nacional

Colección Gral. planos 7101-7102

Colección Orozco y Berra plano núm. 1928 
La explicación de estas paradojas quizá se encuentre si se profundiza la hipótesis del ascenso de un nuevo grupo de latifundistas ("criollos nuevos" según Molina Enríquez), con base en el deslinde de baldios y el desplazamiento de los viejos terratenientes de origen novohispano. La seguridad en la tenencia de Mezquite, por ejemplo, fue amenazada seriamente por el deslinde de baldíos en Zacatecas.

La compañia Calderón y Herrera, concesionaria como dije de los deslindes para Zacatecas, deslindó Mezquite y Pozohondo en 1887, quedando la medición como sigue: ${ }^{17}$

\begin{tabular}{|c|c|c|}
\hline Mezquite & 119.73 & sitios de ganado mayor \\
\hline Pozohondo. & 134.67 & sitios de ganado mayor \\
\hline Excedente ... & 13.94 & sitios de ganado mayo \\
\hline Baldios & 34.34 & ado \\
\hline & 02.68 & nad \\
\hline
\end{tabular}

Las protestas de Miguel Rul, propietario de Mezquite, no se hicieron esperar. Después de perder el caso en Zacatecas, lo llevó a Guadalajara y de ahi a la ciudad de México, directamente a la Secretaría de Fomento. ${ }^{18}$ Las medidas presentadas por Miguel Rul le otorgaban 166 sitios de ganado mayor a Mezquite, sólo 88 a Pozohondo y nada de excedente ni de baldíos. El fallo, dado el peso de Miguel Rul en la política nacional, fue a favor de Mezquite. No obstante, el conflicto ejemplificó el cuestionamiento por nuevas fuerzas sociales a un tipo de propiedad y de producción en crisis.

\section{Economía de una hacienda ganadera}

Se debe a Andrés Molina Enríquezla afirmación de quela hacienda, en condiciones normales, no era un negocio; siguiendo a Jovellanos, escribió que la gran propiedad'era una amortización, una imposición de "vanidad y orgullo" realizada, cito textualmente, "más por espíritu de dominación que por propósitos de cultivo, puesto que en ella se invierte un capital que en condiciones normales no puede producir sino un rédito inferior al de las demás imposiciones (o empresas), si bien es que bajo la forma de una renta segura, perpetua y firme". ${ }^{19}$ En otras palabras, las haciendas cerealeras no eran un buen negocio, el mismo Molina Enriquez da un argumento más al respecto: "Si la agricultura en grande fuera remuneradora, Estados Unidos, dueños de un gran territorio y afecto por instinto a todo lo grande, tendría las más grandes haciendas del mundo. Sin embargo, concluía, no es así". ${ }^{20}$ Insistía Molina Enque $z$ que el hacendado buscaba más la seguridad de la renta que aumento: "El deseo (...) del hacendado es aumentar sus productos en fuerza de ensanchar las fuerzas naturales de ellos, no en fuerza de multiplicar sus trabajos propios". ${ }^{21}$ Es decir, en términos más próximos, la base económica de la hacienda era un proceso de reproducción ampliada, no intensiva, por lo que a través del monopolio de las tierras el hacendado trataba de compensar ia debilidad en la producción; ello, junto con los bajos salarios y jornales y el sistema de préstamos, constituía la "economia de miserias" de las haciendas.

\footnotetext{
17 AGN-FRyA, Caja 341.

18 Miguel Rul fue diputado federal por Aguascalientes.

19 A. Molina Enríquez, op. cit., p. 158.

20 Itid., p. 163.

21 Ibid., p. 167 .
} 
Por lo anterior, existe en Molina Enríquez el reconocimiento no sólo de los motivos de prestigio y de poder en el hacendado, sino también el análisis de la función económica de los latifundios. François Chevalier, en un estudio clásico de los años 50 , insistía en los móviles no económicos para la formación de los latifundios; incluso, pensando en el feudalismo europeo, Chevalier plantearia que la economia de la hacienda se caracterizaba por el autoconsumo. ${ }^{22}$ Estudios recientes sobre la época colonial y el siglo XIX han mostrado que el acaparamiento de tierras partía de una razón económica, pues significaba la eliminación de competidores y la posibilidad de sostener o aumentar las rentas; ello, a su vez, abría a los latifundistas las puertas del prestigio y del poder político. ${ }^{23}$ Por otra parte, el análisis de la contabilidad de las haciendas permitió mostrar que éstas, en términos generales, eran un negocio con su producción orientada al mercado, aunque no necesariamente un buen negocio. ${ }^{24} \mathrm{Se}$ replanteó así la función económica de los grandes latifundios. Sin embargo, se desdeñó la perspectiva crítica sistematizada por Molina Enríquez y anticipada por Wistano Luis Orozco: las haciendas porfiristas no sólo impidieron la autosuficiencia alimentaria, como actualmente se dice, sino también frenaron el desarrollo regional y nacional al imponer una "economía de miseria". El análisis de la rentabilidad de la hacienda de Mezquite, por ejemplo, no puede olvidar el monopolio privado de más de 400 mil hectáreas de un bien socialmente escaso (la tierra), como tampoco los bajos jornales y salarios. Efectivamente, Mezquite fue un negocio, "imposición" o empresa, con relaciones comerciales o mercantiles incluso fuera del país; sin embargo, como trataré de mostrar a continuación, durante el porfiriato no fue un buen negocio, aunque proporcionó a su propietario una renta segura y firme dado el monopolio de la tierra (renta de la tierra) los bajos salarios y jornales (renta del trabajo).

\section{LA HACIENDA GANADERA}

La actividad principal de Mezquite fue la ganadería de tipo extensivo. ${ }^{25}$ Actividad, por cierto, caracteristica de todo el estado de Zacatecas. En 1894, en un informe sobre la geografía y estadística de Zacatecas, Alfonso Luis Velasco comentó que la producción agrícola en dicho estado no era importante. Las causas que argumentó para explicarlo fueron diversas: naturales, como la falta de corrientes de agua; tecni= coeducativas, como la ausencia de maquinaria y de métodos modernos para las labores del campo, y economicosociales, es decir, la mala distribución de la propiedad "pues hay fincas agrícolas que en el Estado

${ }^{22}$ François Chevalier, La formación de los latifundios en México. Tierra y sociedad en los siglos XVI y XVII, Trad. Antonio Alatorre, México, F.C.E., 1975, 510 p.

${ }^{23}$ Magnus Mörner, op. cit.; Charles H. Harris III, A mexican family empire. The latifundio of the Sánchez Navarro, 1765-1867, Austin y Londres, Univ. de Texas, 1975, 410 p.

24 Jan Bazant, "Cinco haciendas..."; op. cit. Juan Felipe Leal y Mario Huacuja, Economía y sistema de haciendas en México. La hacienda pulquera en el cambio. Siglos XVIII, XIX Y XX, México, ERA, 1982, 200 p. Ma. Guadalupe Rodríguez Gómez, Jalapa y San Juan de los Otates. Dós haciendas en el Bajio Colonial, México, El Colegio del Bajío, 1984, $171 \mathrm{p}$.

${ }^{25}$ En promedio, durante el porfiriato, Mezquite destinaba 40 has por cabeza de ganado mayor y 6 has por cabeza de ganado menor. Un coeficiente elevado era, según Leonardo Martín Echeverría, 17 has y 4 has, respectivamente: La ganaderia en México, Banco de México, 1960, $188 \mathrm{p}$. 
(de Zacatecas) llegan a alcanzar una superficie de 251000 hectáreas, y el término medio de ellas es de 8775 hectáreas". ${ }^{26}$ Existían en Zacatecas, sin embargo, haciendas con una superficie mayor a la considerada por Alfonso L. Velasco. Por ejemplo, la misma hacienda de Mezquite y anexas, cuya extensión para 1881 como vimos era de 421000 has., o la hacienda de Cedros, que según Wistano Luis Orozco tenía una superficie de 754912 hectáreas. ${ }^{27}$

El producto principal de las haciendas de Zacatecas era la ganadería. Al respecto Alfonso L. Velasco comentó: "De fama son en toda la República sus haciendas ganaderas", y agregaba: "la superficie que ocupan en el Estado los terrenos pastales es de 3270000 hectáreas (la mitad aproximadamente de la superficie de Zacatecas en aquel momento). En ellas se crían ganado ovino, caprino, bovino, caballar, mular, asnal y porcino; todos muy apreciados". ${ }^{28}$ La ganadería en Zacatecas ocupaba en el año de 1902 el primer lugar nacional en el número de cabezas, destacando el ganado menor. Tenía el $10.6 \%$ de todo el ganado del país y el $19.3 \%$ del ganado menor ${ }^{29}$ Un historiador zacatecano ha visto estas cifras de 1902 como conservadoras. ${ }^{30}$ Según datos de 1889 el número de cabezas de ganado en Zacatecas era de 3561000 , mientras que los datos de 1902 señalan sólo 1548157 (cuadro 3). La diferencia entre uno y otro año es de aproximadamente dos millones de cabezas. Se puede pensar en errores de cálculo. Sin embargo, como veremos más adelante, el descenso de ganado en Zacatecas coincide con las pérdidas de ganado en la hacienda de Mezquite. En su momento intentaré una explicación. Por ahora me interesa señalar el carácter extensivo de la ganadería en Zacatecas, es decir, su vinculación histórica con una forma de propiedad: los grandes latifundios. Aquí adquiere sentido lo anotado por Alfonso L. Velasco para explicar la poca importancia de la producción agrícola-cerealera en Zacatecas, particularmente "la mala distribución de la propiedad". La "ganaderización" del campo mexicano, por lo tanto, no es un proceso reciente. ${ }^{31}$

El análisis de las existencias de ganado en Mezquite puede ejemplificar la situación de la ganadería zacatecana durante el porfiriato. La característica de dichas existencias, entre los años de 1877 y 1911 , fue una marcada tendencia a la baja. Dentro de esta tendencia, sin embargo, pueden distinguirse dos momentos especialmente críticos. El primero de ellos ocurrió en los inicios de los años ochenta del siglo pasado, y tiene que ver concretamente con las existencias de ganado mayor: de 13757 cabezas en 1879 quedaron sólo 4536 en 1887. El segundo momento crítico fue en la década de los años noventa, esta vez vinculado al gana-

${ }^{26}$ Alfonso Luis Velasco, Geografia y estadística de la República Mexicana. Geografia y estadística del Estado de Zacatecas, t. XV, México, Sria. de Fomento, 1894, p. 96.

27 Wistano Luis Orozco, La cuestión agraria, Guadalajara, México, Taller de El Regional, 1911 , p. 29.

28 Alfonso L. Velasco, op. cit., p. 104-105.

29 Antonio Peñafiel, Estadistica ganadera de la República Mexicana, México, Sria. de Fomento, 1902.

${ }^{30}$ Cuauhtémoc Esparza Sánchez, "Historia de la ganadería en Zacatecas, 1531-1911" Anuario de Historia, Universidad Autónoma de Zacatecas, 1978-p. 12-160.

${ }_{31}$ Me parece que no se ha profundizado suficientemente sobre las causas de la insuficiencia de cereales durante el porfiriato. Una hipótesis a trabajar sería la "ganaderización" del campo mexicano desde una perspectiva histórica. Para los últimos veinte años. véase Nicolás Reig, "El sistema ganadero-industrial: su estructura y desarrollo 1960. 1980", Desarrollo agroindustrial y la Ganaderia en México, México, SARH-Coordinación General de Desarrollo Agro-Industrial (Documento de Trabajo núm. 8), 1982, p. 19-239. 


\section{CUADRO 3}

Existencias de ganado en Zacatecas, 1889 y 1902

\begin{tabular}{|c|c|c|c|}
\hline \multicolumn{4}{|c|}{1889} \\
\hline Partidos & Mayor & Menor & Total \\
\hline \begin{tabular}{l} 
Zacatecas \\
Fresnillo \\
Sombrerete \\
Jerez \\
Nieves \\
Mazapil \\
Pinos \\
Ojocaliente \\
Villanueva \\
Juchipila \\
Tlaltenango \\
Nochixtlán \\
\multicolumn{2}{c}{ Total }
\end{tabular} & $\begin{array}{r}29714 \\
66207 \\
24715 \\
27553 \\
16859 \\
14937 \\
19249 \\
4018 \\
47032 \\
7061 \\
27864 \\
6899 \\
302108\end{array}$ & $\begin{array}{r}07668 \\
93592 \\
16183 \\
7451 \\
33475 \\
30507 \\
71640 \\
9342 \\
0625 \\
728 \\
10335 \\
1503 \\
1276052\end{array}$ & $\begin{array}{r}37382 \\
59799 \\
40898 \\
75004 \\
50334 \\
45444 \\
90889 \\
23360 \\
87657 \\
20789 \\
38199 \\
8402 \\
1548157\end{array}$ \\
\hline \multicolumn{4}{|c|}{1902} \\
\hline Partidos & Mayor & Menor & Total \\
\hline \begin{tabular}{l} 
Zacatecas \\
Fresnillo \\
Sombrerete \\
Jerez \\
Nieves \\
Mazapil \\
Pinos \\
Ojocaliente \\
Villanueva \\
Juchipila \\
Tlaltenango \\
Nochixtlán \\
\multicolumn{2}{c}{ Total }
\end{tabular} & $\begin{array}{r}90400 \\
135000 \\
63420 \\
94050 \\
38020 \\
104650 \\
25750 \\
12300 \\
55610 \\
11100 \\
20980 \\
9100 \\
660380\end{array}$ & $\begin{array}{r}27000 \\
48100 \\
2700 \\
600 \\
4100 \\
1154800 \\
45700 \\
8800 \\
12200 \\
300 \\
2600 \\
4700 \\
2840600\end{array}$ & $\begin{array}{r}17000 \\
83000 \\
6120 \\
02650 \\
32120 \\
1391570 \\
72450 \\
1100 \\
7810 \\
2400 \\
3580 \\
3800 \\
356100\end{array}$ \\
\hline \multicolumn{2}{|c|}{$\therefore$} & Partidos & $\begin{array}{c}\text { Diferencia de } \\
\text { Totales }\end{array}$ \\
\hline $\begin{array}{l}\text { Fuentes: Para } \\
\text { lla, Memoria s } \\
\text { productos en el } \\
\text { cit. pos. Cuauh } \\
\text { "Historia de la } \\
1531-1911 \text { "'en } \\
1978, \text { p. 12-160 } \\
\text { Estadística gano } \\
\text { xicana, Sría. de }\end{array}$ & $\begin{array}{l}\text { Arbol y Boni- } \\
\text { ricultura y sus } \\
\text { acatecas } 1889 \text {, } \\
\text { arza Sánchez. } \\
\text { en Zacatecas, } \\
\text { Historia UAZ, } \\
\text { 2: A. Peñafiel, } \\
\text { República Me- } \\
1902 \text {. }\end{array}$ & \begin{tabular}{l} 
Zacatecas \\
Fresnillo \\
Sombrerete \\
Jerez \\
Nieves \\
Mazapil \\
Pinos \\
Ojocaliente \\
Villanueva \\
Juchipila \\
Tlaltenango \\
Nochixtlán \\
\multicolumn{1}{c}{ Total } \\
.
\end{tabular} & $\begin{array}{lr}-\quad 80018 \\
-\quad 23201 \\
-\quad 64778 \\
-\quad 27646 \\
& 18214 \\
-1246126 \\
-\quad 80561 \\
-\quad 37740 \\
& 19847 \\
- & 8389 \\
- & 5381 \\
- & 65398 \\
-2012843\end{array}$ \\
\hline
\end{tabular}


do menor: de 76822 cabezas para 1891 se registraron sólo 23621 para 1895, una diferencia de más de 50 mil cabezas en cuatro años (cuadro 4 y gráfica 1). Si se observa el valor de las existencias puede notarse una caida semejante a la del número de cabezas. Pero hay un cambio importante en el valor: con la pérdida de ganado menor, el valor del ganado mayor comenzó a superar al del ganado menor a partir de 1895 (gráfica 2). Ello significó una transformación importante en el giro de la hacienda. Para entender este cambio es indispensable explicar, primero, el comportamiento de las existencias en general. Hay varias causas: la natural falta de agua en la región combinada con fuertes sequias desde fines de los años setenta; la mala administración y, fundamentalmente, las transformaciones en los mercados ganaderos, la caída del precio de la lana, junto con el de la plata y los cambios en la producción minera nacional.

\section{CUADRO 4}

Existencias de Ganado en Mezquite, 1877-1911

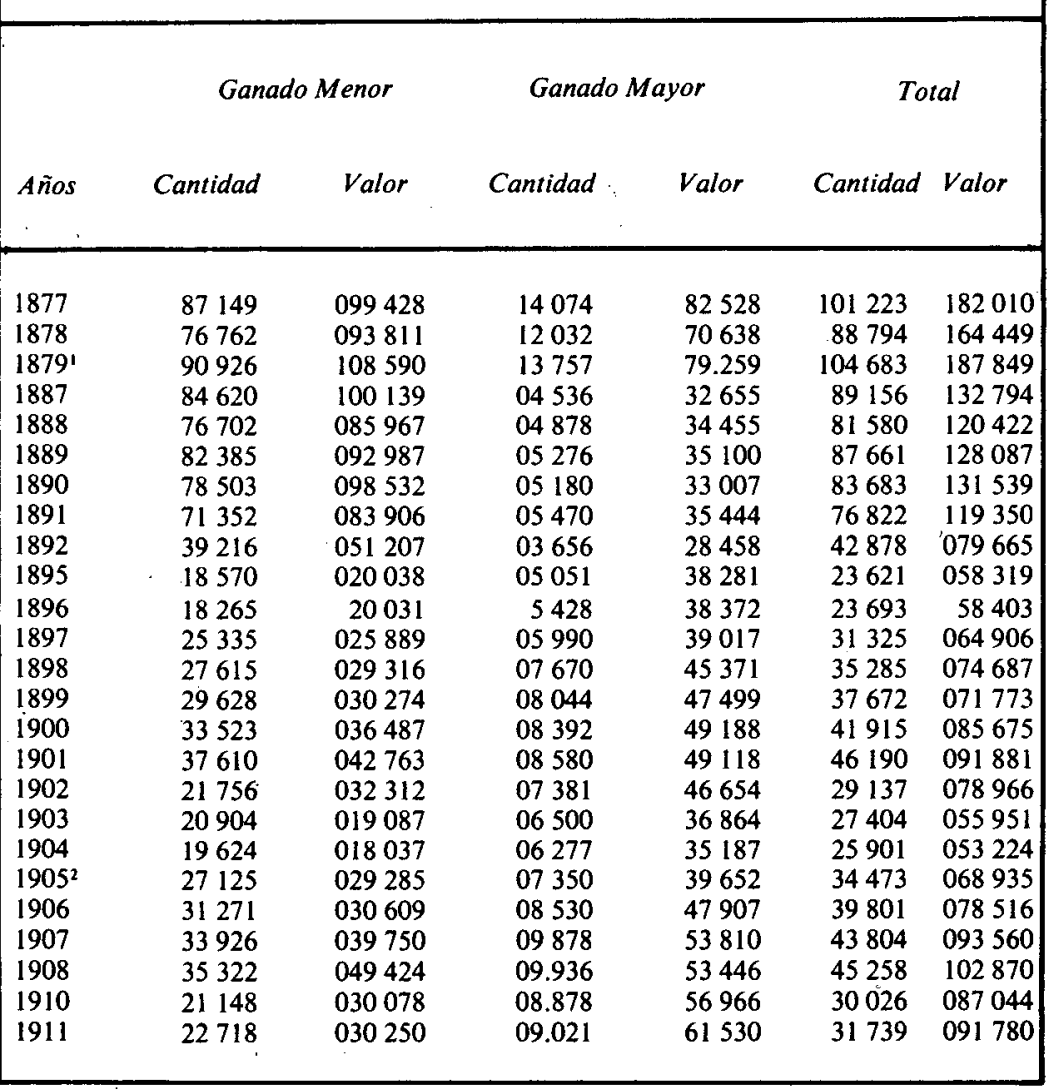

Fuente: AGN-FRyA, Caja 196, 344, 342, 338, 340, 110, 92, 93, 38 AM/1, 2, 3, 73, 74, y 215.

Notas: 1 A enero de 1880.

2 A partir de 1905 , marzo de cada año. 

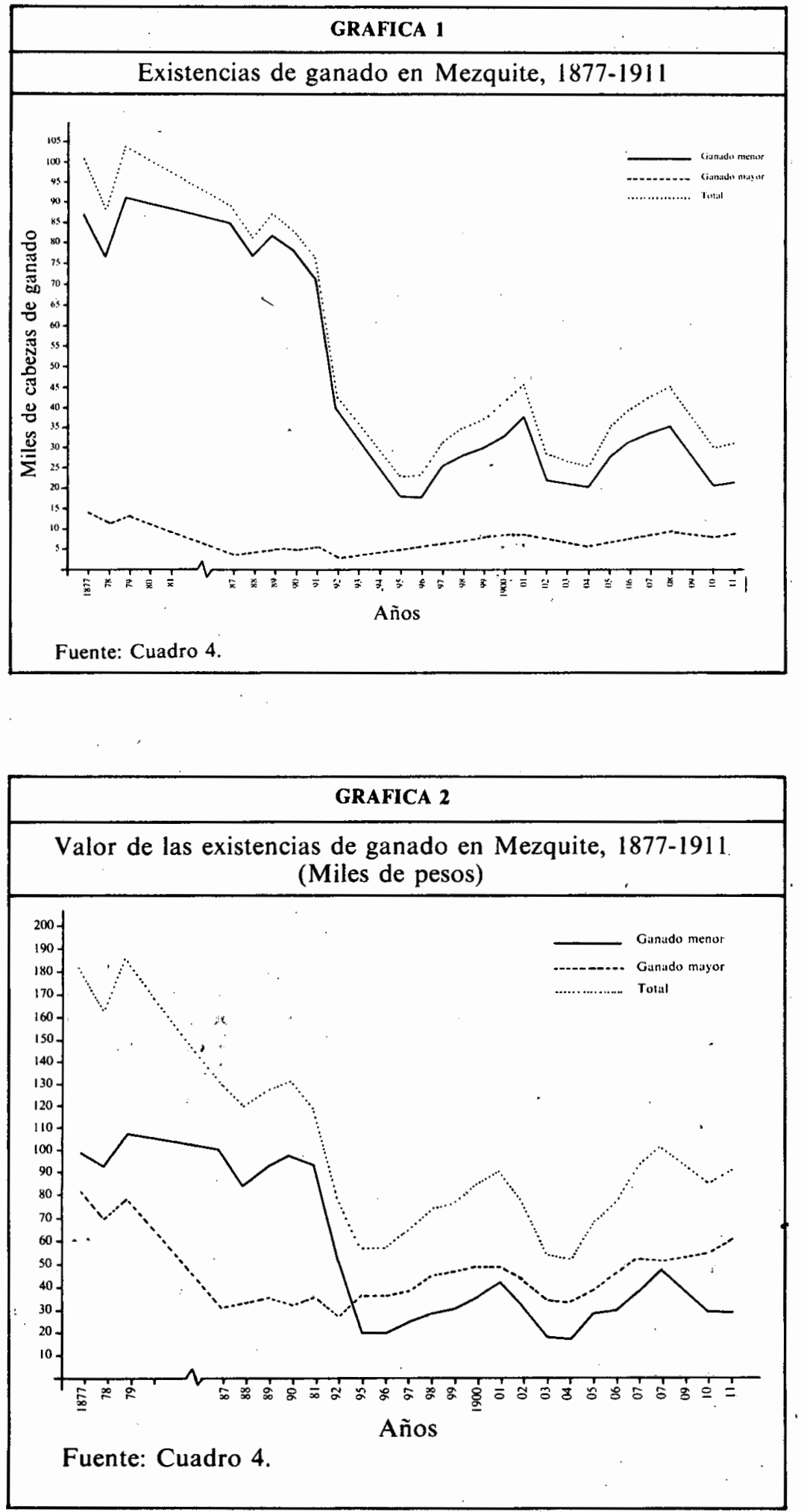
En abril de 1878 el administrador de Mezquite, José P. Berúmen, envió a su patrón Miguel Rul, quien vivia en la ciudad de México, algunas observaciones sobre la cría de ganado lanar. ${ }^{32}$ En ellas juzgó como principal obstáculo para la cría y la mejora del ganado la aridez del terreno que, unida a la escasez y la irregularidad de las lluvias, imposibili-' taba el crecimiento de buenos pastos. Quince años más tarde (1893) el mismo administrador, en una carta de respuesta a las acusaciones de mala administración que hiciera Miguel Rul en su contra, argumentó que las pérdidas de los últimos cinco años de su administración habían sido ocasionadas por "calamidades (naturales) verdaderamente desastrosas". Agregaba además que durante su administración le había dado ganancias, "a pesar de tantos desastres sufridos en 21 años con especialidad los de 1875 y otros varios antes de los últimos cinco años expresados (1889-1893), pésimos sin interrupciones". ${ }^{33}$ Asi pues, para el administrador principal de Mezquite las pérdidas de la hacienda, es decir, las existencias decrecientes de ganado se explican y hasta justifican por los desastres naturales, en particular por la escasez de lluvias.

Úna causa más de la disminución en las existencias de ganado en Mezquite puede encontrarse en la mala administración ganadera. El administrador J.P. Berúmen fue despedido en 1893 después de 24 años de servicio a la familia Rul. Las acusaciones de Miguel Rul a su administrador fueron: administración desordenada, cuentas ficticias, negocios con ganados y sirvientes de la hacienda, gastos no productivos ni comprobados, etc. La respuesta de J.P Berúmen fue directa a cada acusación: después de 24 años se juzgaba su administración desordenada y con cuentas ficticias; siempre tuvo cuentas propias pero con consentimiento del mismo dueño; todos los gastos fueron justificados, etc. ${ }^{34} \mathrm{En}$ septiembre del mismo año de 1893 el nuevo administrador de Mezquite, Agustín Ramírez, presentó a Miguel Rul un informe en el que señalaba la política desafortunada de ventas de la anterior administración: "Pongo este estadito (de cuentas) para que el Sr. Rul vea las inconvenientes ventas de ganado menor añejo y primal, que hacia la administración pasada, dando a ganar (al comprador) en lo primero (añejo) de lana más de 1.00 peso en cabeza, y en lo segundo (primal) más. La prueba de lo antes dicho es que el Sr. Borbolla compraba 4, 6 u 8 pastorías de carneros añejos, los dejaba en el mismo agostadero y al cabo de un año, y hasta 2 , que los sacaba, hacía un buen negocio." ${ }^{35} \mathrm{La}$ inconveniente política de ventas, por lo tanto, también puede considerarse para explicar la disminución de las existencias de ganado. Sin embargo, el hecho de que después de 24 años Miguel Rul se diera cuenta de la mala administración, significa que debe existir una explicación que rebase el nivel micro y que atienda a causas macroeconómicas.

Durante el siglo XIX Mezquite tuvo sus principales mercados en los centros mineros, en particular Zacatecas y Guanajuato. En octubre de i800, por ejemplo, dos años después de haber adquirido Mezquite, el conde Pérez Gálvez compró por la cantidad de 1500 pesos de oro común una Casa de Matanza en Fresnillo, Zac. ${ }^{36}$ Para 1805 existe información de que los principales productos o subproductos ganaderos de

32 AGN-FRyA, Caja 344.

33 Ibid., Caja 80.

34 Ibid., J. P. Berúmen antes de trabajar en Mezquite lo había hecho en la hacienda de Bocas, San Luis Potosí.

3s AGN-FRyA, Caja 180.

36 AGN-FRyA, Caja 28 AM/1. 
Mezquite (lana, sebo, carne, jabón, zaleas, etc.) fueron enviados a los estados de Zacatecas y Guanajuato, e incluso a la ciudad de México. ${ }^{37}$ Esta tendencia se orientó lógicamente hacia Źacatecas dado el auge minero de Fresnillo después de la independencia (entre 1830 y 1860 se puede situar el auge del mineral Proaño). Así, con la decadencia de la minería de Fresnillo, dado el ciclo depreciativo de la plata y las transformaciones en la industria minera nacional a favor de los minerales industriales a partir de los años noventa, la ganadería zacatecana, y entre ella la mezquiteña, sufrió una baja considerable. ${ }^{38}$

Otro elemento explicativo se refiere al mercado externo. Un historiador zacatecano señaló que, en la época de Porfirio Díaz, el grueso de la producción de ganado bovino salía de Zacatecas: a Aguascalientes, a Guanajuato, a Querétaro, a la ciudad de México, e incluso a Texas. En 1887, por ejemplo, un revendedor de San Antonio, Texas, compró 6300 reses en las haciendas de Mezquite y Sierra Hermosa. ${ }^{39}$ Con la construcción del Ferrocarril Central Mexicano, el cual pasaba por Mezquite (Mapa), el ganado norteño mexicano comenzó a abastecer la creciente demanda de carne de los centros urbanos estadunidenses, dentro del proceso de expansión de la frontera agrícola ganadera de esé país. ${ }^{40}$ En 1890 , sin embargo, el gobierno estadunidense decretó una disposición conocida como la "ley Mac Kinley", con la cual impuso severos gravámenes al ganado mexicano que entrara al territorio de los Estados Unidos. Dicha ley se derogó en 1895, pero el daño a las exportaciones estaba hecho. ${ }^{41}$ Estos años de proteccionismo estadunidense coinciden con los años más críticos de la ganadería zacatecana, en especial del ganado menor. De hecho, a partir de 1895, el ganado mayor se recuperó, como lo muestra el caso de Mezquite; en cambio, el ganado menor, y las haciendas que lo explotaban, entraban en una crisis insalvable. Los subproductos del ganado menor (particularmente la lana) sufrieron una caída de precio no sólo a nivel nacional, sino también internacional, ${ }^{42}$ a partir de los años setenta.

En síntesis, el descenso en las existencias de ganado, principalmente menor, en la hacienda de Mezquite, tuvo que ver no sólo con las fuertes sequías, la carencia natural de agua en la región, la mala administración, sino también de manera primordial con la contracción de los mercados, nacionales e internacionales. Por esto último, la administración de Mezquite no pudo (ni lo deseó realmente) sortear la crisis.

37 AGN-FRyA, Caja 28 AM/11. Es interesante observar que durante el auge de Guanajuato a principios del siglo XIX, Mezquite funcionó dentro de un complejo sistema de minas haciendas administrado por el conde Pérez Gálvez.

38 Guadalupe Nava Oteo, "La Mineria", Historia Moderna... op. cit. p. 179-310.

39 Cuauhtémoc Esparza, op. cit.

40 Fernando Rosenzweig H., "Las exportaciones mexicanas de 1877 a 1911 ", Historia Mexicana, vol. IX: 3, (85), enero-marzo de 1960, p. 402. Manuel Machado Jr., The north mexican cattle industry, 1910-1975, Texas University, 1981, 152 p. Marco Bellingeri e Isabel Gil, "Las estructuras agrarias bajo el Porfiriato", México en el siglo XIX (182I-19I0). Historia económica y de la estructura social, México, Ed. Nueva Imagen, 2a. ed., 1981, p. 315-338.

${ }^{4 !}$ Eduardo Soto Izquierdo, et al, Panorama de la ganadería mexicana, México, Centro Nacional de Investigaciones Agrarias, 1983, p. 63.

42 Eric J. Hobsbawm, Industria e Imperio, Barcelona, Ed. Ariel, 1977, p. 191. 


\section{LA CONTABILIDAD}

El estudio de la contabilidad de Mezquite lo realicé basándome en 25 inventarios de diferentes años durante el porfiriato y utilizando la técnica de los balances comparativos. Con ello es posible fundamentar la hipótesis de que Mezquite, si bien fue un negocio (émpresa o "imposición", según el término y Molina Enriquez) con una administración moderna, no fue un buen negocio. ${ }^{43}$ El "capital contable" (concepto utilizado sólo en sentido administrativo: diferencia anual entre activos y pasivos) de la hacienda de Mezquite, en general, sufrió disminuciones durante el porfiriato. No obstante, si se observa con detalle, dicho capital presentó aumentos de 1878 a 1887 , de 1896 a 1898, de.1899 a 1901, y finalmente de 1903 a 1910 . Se debieron fundamentalmente al aumento de los activos, al mismo tiempo que disminuían los pasivos. Es decir, se debieron al incremento de los créditos activos (1878-1887) y, sobre todo, al aumento del valor del ganado (véase gráfica 3 ).

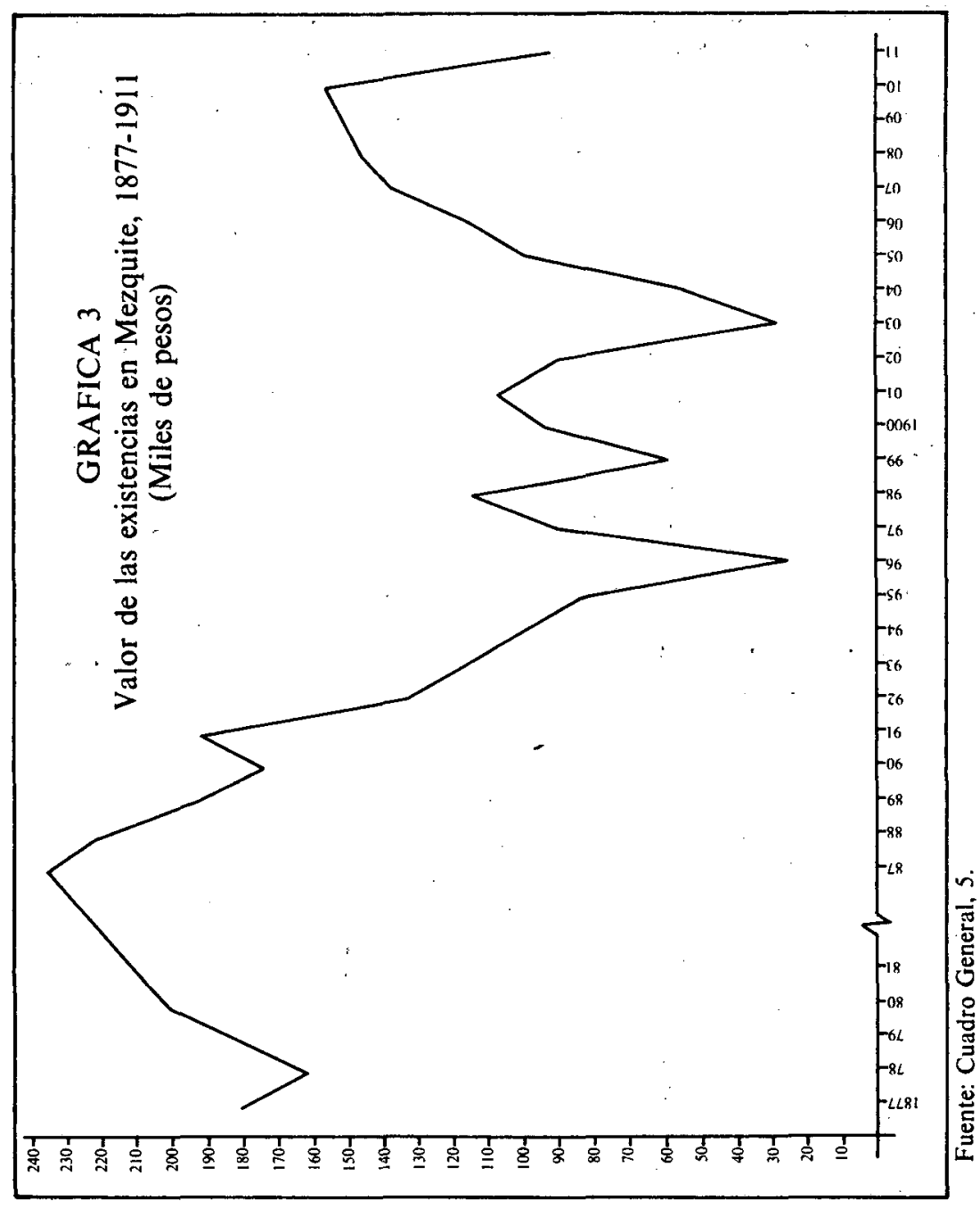

43 Sobre los términos de empresa y beneficio, véase Pierre Vilar, Economía, Derecho, Historia, Barcelona, Ed. Ariel, 1983. 


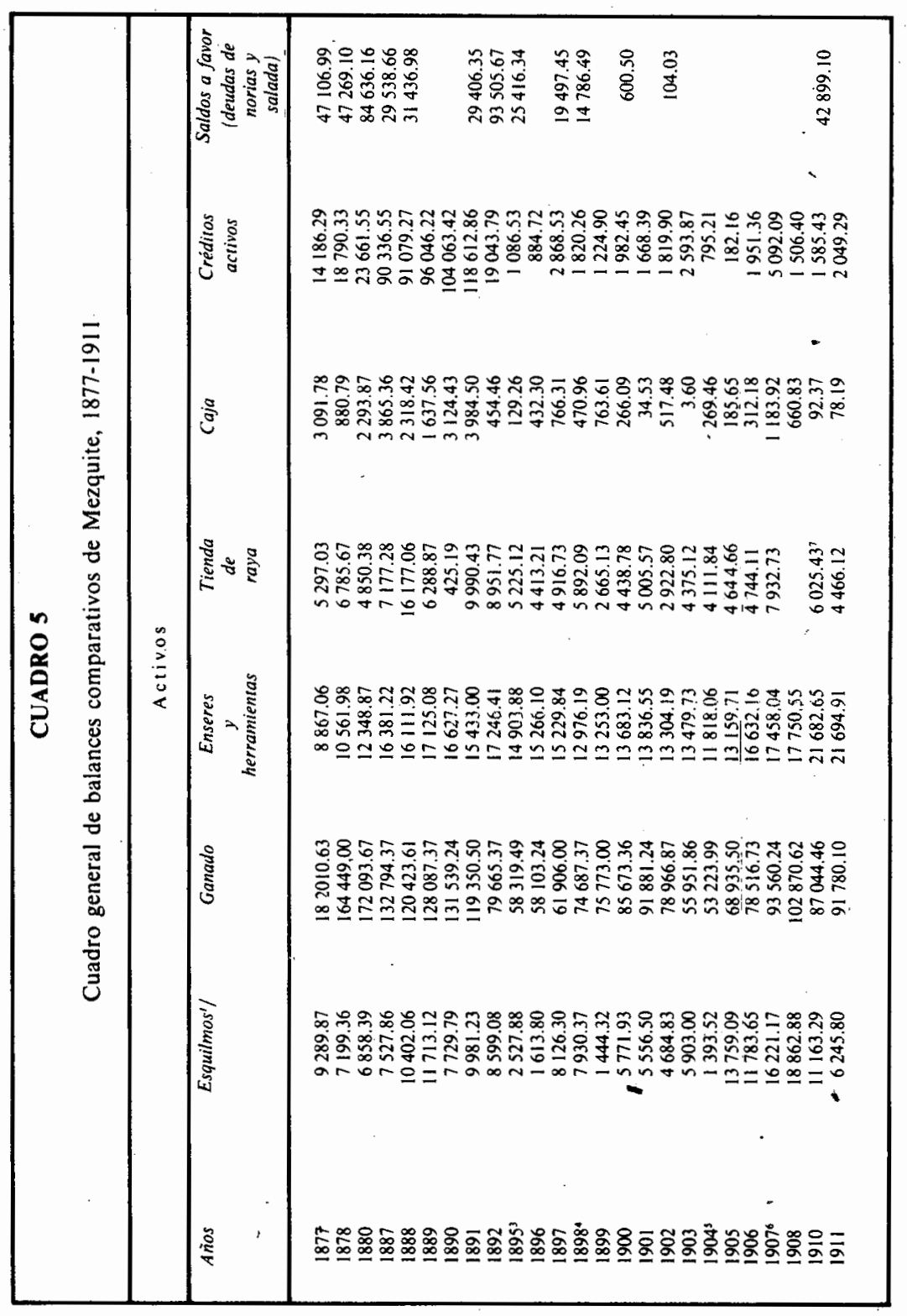




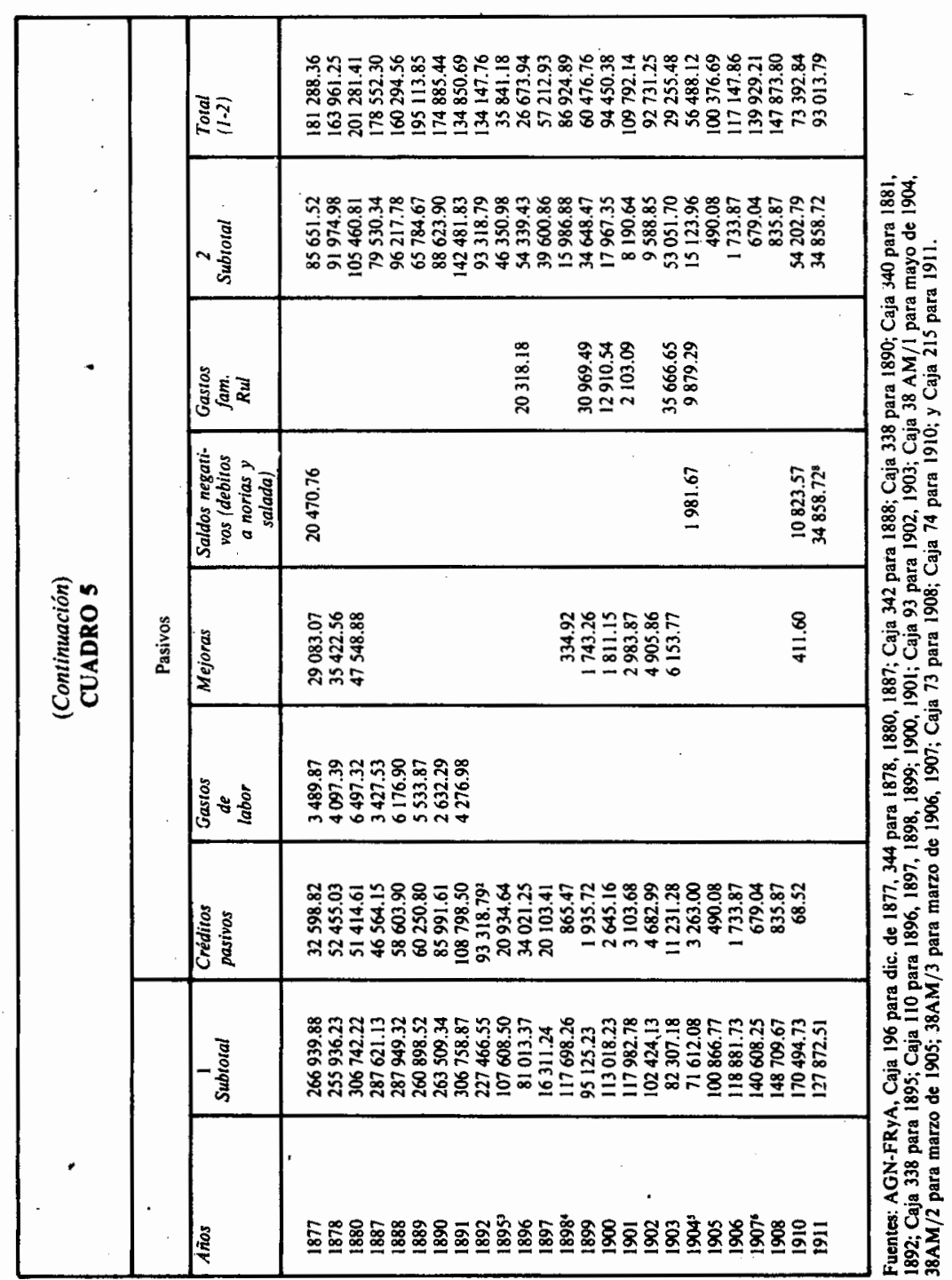


Como lo anticipé, la disminución del capital contable de Mezquite, pese a los aumentos, fue la característica más notable de la contabilidad de la empresa durante el régimen de Porfirio Díaz. Al respecto, sobresale el periodo que va de 1887 a 1896 , a unque también el capital disminuyó en los años 1898-99, 1901-03 y 1910-11. Para explicar estos descensos es necesario recordar el comportamiento del valor de las existencias de ganado, en concreto la caída de dicho valor en la década de los años noventa del siglo pasado (sobre la cual he intentado, a su vez, una explicación en el apartado anterior). Pero los descensos del capital contable tienen que ver también con los créditos, tanto activos como pasivos (cuadro 5 y gráfica 3 ).

Primero los créditos activos. Tradicionalmente se ha observado a la hacienda típica más como deudora que como acreedora sobre todo durante la época colonial y en relación con la Iglesia. Según los inventarios de Mezquite, esta hacienda fue también un gran agente acreedor principalmente entre los años de 1887 y 1891 . En este último año, por ejemplo, los créditos activos alcanzaron la cifra de 118612.86 pesos, aproximadamente el $40 \%$ del total de los activos de la empresa. A partir de ese mismo año dichos créditos descendieron drásticamente, hasta representar un porcentaje insignificante de los activos (cuadro 5).

Por su parte, los créditos pasivos de Mezquite alcanzaron el mismo año de 1891 la cifra de 108798.50 pesos, prácticamente el total de los pasivos. La diferencia con los créditos activos fue que los pasivos mantuvieron un porcentaje importante dentro del total (de pasivos) hasta 1897. En otras palabras, los créditos pasivos, en particular durante los años noventa del siglo pasado, incidieron negativamente en el comportamiento del capital contable. Las deudas, por lo tanto, como un ejemplo más de administración ineficiente, contribuyeron a disminuir el capital contable de Mezquite durante los años críticos de 1891-97.

De la contabilidad en general hay otros factores dignos de mencionarse. Por ejemplo, los gastos de mejoras que se registran entre 1877 1879 , gastos que se olvidan prácticamente en los años siguientes. Ello está relacionado con la idea expresada por Molina Enriquez de que los hacendados no reinvertian sus ganancias. La afirmación es correcta, aunque debe ser matizada. Los gastos de mejora de 1877-79 en Mezquite tienen que ver con un proceso general de modernización de la hacienda, incluyendo desde luego una administración racional. Pero este proceso fue por lo menos contradictorio: se contaba con una administración moderna pero no eficiente, como lo dejan ver concretamente las políticas de ventas y de créditos. Además, el proceso no se reprodujo debido, no sólo a la suspensión de los gastos de mejoras (exceptuando los primeros seis años de este siglo en los que se invierte una minima cantidad), sino también debido a los altos gastos de los propietarios, principalmente los años de 1896, 1899 y 1903 (cuadro 5).

Notas: 1. Incluye existencias de cereales, pieles, zaleas, sebo, lana, tequesquite y matanza.

2. No se considera un préstamo al gobierno del Estado por $\$ 15,824.79$

3. La administración había cambiado de J. I. Berúmen a Daniel de la Torre,

4. A la muerte de Miguel Rul, la administración pasó a Ladislao Ireneo Vega.

5. Administra Pedro Galaviz

6. Administra Vicente Godoy

7. Incluye almacén $\$ 2,391.24$

8. Gastos generales. 
En síntesis, durante el porfiriato, Mezquite fue una haciendaempresa con una ganaderia superextensiva, con una productividad decreciente y un capital contable mermado. No fue un buen negocio, aunque el propietario lo sostuvo por razones de prestigio y poder, y por que le proporcionaba una renta segura, gracias al monopolio de la tierra (lo cual le proporcionaba materia prima sin costo alguno: los pastos) y a los bajos salarios y jornales (como lo veremos en el próximo apartado). Desde una perspectiva crítica, puede concluirse que la gran propiedad subutilizó los recursos de la región en la que se impuso. En este sentido, limitó las posibilidades de un temprano desarrollo regional.

\section{El trabajo forzoso}

No obstante ser uno de los aspectos más polémicos, las condiciones de trabajo en las haciendas durante el porfiriato han sido poco estudiadas. Quizá tenga esto su explicación no sólo en las dificultades para obtener información de primera, sino también, en palabras de Enrique Florescano, por la "leyenda negra" que la revolución de 1910 levantó contra la hacienda. ${ }^{44} \mathrm{La}$ interpretación oficial sobre las haciendas, parte importante de la ideología de la revolución, acentuó algunos elementos de la realidad (por ejemplo, las condiciones de semiesclavitud existentes en algunas haciendas del sur del país: México Bárbaro),${ }^{45}$ justificando asi las acciones del régimen revolucionario en materia de reforma agraria. La fuerza de esta interpretación, aún vigente, dificultó el replanteamiento de las condiciones de trabajo en las haciendas porfiristas.

Quizá con menos vigor que la anterior, subsiste también, y se fortalece por la crisis de la ideología de la revolución, la "leyenda blanca" sobre las haciendas. Un ejemplo reciente, con todas las pretensiones científicas de un académico estadunidense, lo es Harry E. Cross. Este autor, en contraposición a la interpretación de que el trabajo en las haciendas mexicanas era de virtual esclavitud, ha desarrollado la idea de que la familia promedio de las haciendas, en particular de Zacatecas durante el siglo XIX, tuvo condiciones de vida adecuadas: buena alimentación, vivienda, educación, trabajo no coercitivo (la tienda de raya ofrecía incluso precios más bajos), etc. ${ }^{46}$ Posteriormente ampliaría sus consideraciones para el estado de San Luis Potosí y para el siglo XVIII, aunque resaltando la dieta de la población rural de la región, como lo deja ver su conclusión temeraria: "No debe por tanto sorprender que el hambre haya sido virtualmente desconocida para los hombres comunes de esta región en los siglos XVIII y XIX". ${ }^{47}$ No obstante que el autor citado utiliza los libros de contabilidad de algunas haciendas, cae en los mismos esquemas y generalidades de la interpretación que cuestiona. Por ejemplo, no desarrolla dos elementos fundamentales: la deuda y los salarios de los trabajadores agrícolas.

\footnotetext{
${ }^{44}$ Enrique Florescano, Origen y desarrollo de los problemas agrarios de México, 1500 1821, México, ERA, 4a. ed., 1981, p. 105-109.

4s Turner, John Kenneth, Méxiço Bárbaro. Ensayo Sociopolítico, México, B. CostaAmic ed., 1974.

${ }^{46}$ Harry E. Cross, "Living standards in Rural Nineteenth-Century México: Zacatecas 1820-1880", Journal of Latin American Studies, vol. 10:1, mayo 1978, p. 1-19.

${ }^{47}$ Ibid., "Dieta y nutrición en el medio rural de Zacatecas y San Luis Potosí (siglosXVII y XIX)”, Historia Mexicana, vol. XXI:I, (121), julio-sept. 1981, p. 113.
} 
Por fortuna, existen estudios cuidadosos, orientadores excelentes en la investigación, que superan las leyendas. Me refiero concretamente a los trabajos de Moisés González Navarro (indica ya algunas diferencias regionales, por ejemplo respecto a los salarios); de Fernando Rosenzweig (sobre la disminución del salario real en las labores agrícolas); de Jan Bazant (además de utilizar ya los libros de cuentas, resalta los diferentes tipos de trabajo dentro de una misma hacienda); en fin, de Friedrich Katz (sintesis indispensable sobre la servidumbre agraria durante el porfiriato). ${ }^{48}$ Puede decirse entonces que los estudios sobre las condiciones de trabajo en las haciendas, si bien son escasos, cuentan con excelentes guías.

\section{ESTRATIFICACION Y DEUDAS}

La información que ofrece el archivo de la familia Rul sobre las condiciones de trabajo en Mezquite no es, por desgracia, abundante. Sin embargo, la existente permite entrar en la discusión y precisar en lo posible algunas cuestiones sobre el tema. Primero analizaré la organización o estratificación social de la hacienda, definiendo las distintas categorías de trabajo. Posteriormente desarrollaré dos aspectos que he considerado fundamentales: el endeudamiento y los salarios de los trabajadores.

He preferido el concepto de trabajadores agrícolas porque engloba tanto a la servidumbre agraria como a los dependientes. El término de peón, en el caso de una hacienda ganadera norteña, es muy restringido pues se refiere sólo a los trabajadores de la labor. Teniendo en cuenta lo anterior, los trabajadores de Mezquite pueden clasificarse en dependientes (tanto principales como secundarios), y en sirvientes (permanentes o acomodados y temporales o alquilados). La base de esta clasificación es principalmente el nivel de ingreso. Así, los dependientes llamados principales comprenden a las personas con ingresos mensuales (salario más ración de maíz) entre 21 y 100 pesos; concretamente: el administrador (el único en recibir los 100 pesos mensuales); el escribiente; los dependientes de la tienda, de las trojes y de las estancias; el capellán y el mayordomo del ganado menor. Los dependiendientes secundarios son aquéllos con un ingreso mensual (salario más ración de maiz) entre 10 y 20 pesos: el preceptor; el director de música; el rayador; los ayudantes del mayordomo del ganado menor; el mayordomo de la labor; los caporales de la caballada, del avio y de las estancias, y el montero.

Para los sirvientes, ya fueran permanentes o alquilados, el criterio de clasificación incluyó a los trabajadores con ingresos entre 1 y 9.99 pesos mensuales. Sin embargo, hay una diferencia importante entre los permanentes y los alquilados. Estos últimos - además de que, como su nombre lo indica, eran temporales y por lo tanto su pago era por determinadas jornadas - no recibían ración de maíz. Fue un mecanismo para que los sirvientes alquilados se mantuvieran endeudados específicamente con la tienda de raya..$^{49}$

${ }^{48}$ M. González Navarro, "la vida social", op. cit., Fernando Rosenzweig, “El desarrollo económico de México de 1877 a 1911 ", El Trimestre Económico, vol. XXII:3, núm. 127, julio-sept. de 1965, p. 446-447; en especial, Jan Bazant, "Peones, arrendatarios y aparceros en México, 1851-1853”, Historia Mexicana, vol. XXIII:2, (90), p. 330-357 y. "Peones, arrendatarios y aparceros: 1868-1904", Historia Mexicana, vol. XXIV:1, (93), p. 94-121. Friedrich Katz, La servidumbre agraria en México en la época porfiriana, trad. A. Sánchez, México, ERA, 1980, 115 p. Otras síntesis importantes: Magnus Mörner, op. cit., y E. Florescano, op. cit.

49 Para esta clasificación me he basado principalmente en la distribución de trabajos de la hacienda, encontrados en AGN-FRyA, Cajas 110 y 210. 
Debo aclarar que la anterior clasificación no coincide totalmente con la organización de trabajos de la administración de Mezquite. La diferencia está en que la administración de la hacienda consideraba dentro de los sirvientes permanentes una división más: los "de a pie" y los "de a caballo". Yo no la retomo porque algunos "de a caballo" los he incluido como dependientes secundarios. Por otra parte, no he mencionado a los arrendatarios debido a que prácticamente no encontré información sobre ellos en los libros de Mezquite.

Tan variado era el nivel de ingreso de los trabajadores de Mezquite como múltiples los trabajos desempeñados. Los dependientes realizaban un trabajo administrativo directivo, el cual implicaba por lo menos saber leer y escribir (administrador, escribiente, dependientes en la tienda y en las trojes, preceptor, capellán, etc.). Los sirvientes, en cambio, estaban asignados a actividades en la casa principal, con el ganado mayor o menor, en la labor o el monte, en la conservación de las fincas, etc. Existia una clara división del trabajo y una escasa movilidad social.

Habiendo reconocido la heterogeneidad social de una hacienda, es el momento de pasar a uno de los problemas esenciales: el endeudamiento de los trabajadores. Enrique Florescano ha explicado el origen y la. permanencia del peonaje no sólo por la deuda (explicable a su vez por los bajos jornales), sino también por la desarticulación de la comunidad indigena. Este argumento, sin embargo, se refiere específicamente a las condiciones del centro del país. ${ }^{50}$ Por otra parte, estudios recientes sobre las haciendas del Bajio en el siglo XVIII, realizados por David Brading, descubrieron que los peones se encontraban atados no por las deudas, "sino por el miedo de perder salarios aún no pagados". ${ }^{51}$ No obstante, de acuerdo con F. Katz, en el norte del pais, durante el porfi-. riato, predominaron diversas formas de trabajo forzoso, debido a que el aumento de la demanda de productos agrícolas de la región fue acompañado por la escasez de mano de obra. Ello se corrobora con el dato aportado por M. González Navarro de que en el norte, pese a la constitución de 1857, "continuó ratificándose legalmente el peonaje".

En la hacienda de Mezquite, durante el porfiriato predominó de hecho el trabajo forzoso a través del endeudamiento, aunque con algunas especificidades. De 1877 a 1892 la deuda de los dependientes fue la más alta en términos comparativos con los sirvientes, contratistas y fleteros de la empresa. A partir de 1896 , debido tanto a la situación crítica del latifundio como a la nueva administración, los dependientes pasaron a ser acreedores de Mezquite (cuadros 6 y 7). Para ellos, por lo tanto, puede aplicarse lo sugerido por D. Brading, en el sentido de que permanecieron en la hacienda durante los años críticos (a partir de 1892) no por sus deudas sino por el miedo a perder sus salarios no pagados.

Los sirvientes, por el contrario, salvo el año de 1896 , siempre estuvieron endeudados con la empresa durante el porfiriato. De hecho, desde fines del siglo pasado hasta la revolución, los créditos activos de Mezquite estuvieron concentrados en los sirvientes (cuadro 6). Es importante aclarar que se trata de los sirvientes permanentes. La deuda de los sirvientes alquilados o temporales tiene que ver más con la tienda de raya que con los créditos activos de la empresa. Es decir, la deuda de es-

so E. Florescano, op. cit.

st David Brading, "Estructura de la producción agricola en el Bajio, 1700-1850", $\mathrm{Ha}$ ciendas, latifundios... op. cit., p. 114. 
tos sirvientes, debido a su trabajo temporal, era contabilizada en la tienda de raya (cuadro 8). En este sentido, además de la venta de mercancías, la tienda de raya controlaba el trabajo de los alquilados. Así pues, la coacción del trabajo a través de la deuda es aplicable sobre todo para los sirvientes. Es decir, el trabajo forzoso en Mezquite se concentró en los sirvientes, intensificándose en los años noventa, en lo cual la tienda de raya cumplió un papel activo para los alquilados.

Contratistas (arrendatarios, medieros y tercieros) y fleteros tuvieron también una participación en los créditos activos de la empresa, principalmente entre 1877 y 1892 . Los primeros volverian a endeudarse hasta los años de 1906-08 (cuadro 6).

\begin{tabular}{|c|c|c|c|c|c|c|}
\hline ' & \multicolumn{5}{|c|}{$\begin{array}{c}\text { CUADRO } 6 \\
\text { Créditos activos de Mezquite, 1877-1911 } \\
\text { (Pesos) }\end{array}$} & \multirow[b]{2}{*}{ Total } \\
\hline Años & Dependientes & Fleteros & Sirvientes & Contratistas & Subtotal & \\
\hline 1877 & 2355.90 & 369.21 & & 377.36 & 3102.47 & $14 \cdot 186.29$ \\
\hline 1878 & 3930.49 & 586.53 & 1579.76 & 662.40 & 6759.18 & 18790.33 \\
\hline 1880 & 4162.36 & 282.98 & 2460.71 & 620.00 & 7526.05 & 23661.55 \\
\hline 1887 & 6827.99 & 1538.10 & 4897.18 & 1519.01 & 14782.28 & 90336.55 \\
\hline 1888 & 6988.66 & 1669.13 & 4348.20 & 1845.07 & 14851.06 & 91079.27 \\
\hline 1889 & 7466.51 & i 935.60 & 5751.69 & 2139.84 & 17293.64 & 96046.22 \\
\hline 1890 & 8751.43 & 1940.55 & 6.065 .16 & 1669.41 & 18426.55 & 104063.42 \\
\hline 1891 & 10607.17 & 1984.70 & 7369.15 & 1679.23 & 21640.25 & 118612.86 \\
\hline $1892^{*}$ & 8225.91 & 1.250 .23 & $3532.89^{1}$ & 263.88 & 13272.91 & 19043.79 \\
\hline 1895 & 499.03 & & 587.50 & & 1086.53 & 1086.53 \\
\hline 1896 & & & 884.72 & & 884.72 & 884.72 \\
\hline 1897 & 313.01 & & 1.105 .52 & & 1418.53 & 2868.53 \\
\hline 1898 & & & & & & 1820.26 \\
\hline 1899 & & & 392.00 & & 392.00 & 1224.90 \\
\hline 1900 & & & 696.47 & & 696.47 & 1982.45 \\
\hline 1901 & & & 845.73 & & 845.73 & 1668.39 \\
\hline 1902 & & & 1611.65 & & 1611.65 & 1819.90 \\
\hline 1903 & & & 2593.87 & & 2593.87 & 2593.87 \\
\hline 1904 & & & 795.21 & & 795.21 & 795.21 \\
\hline 1905 & & & 182.16 & & 182.16 & 182.16 \\
\hline 1906 & & & 567.76 & $1003.20^{2}$ & 1570.96 & 1570.96 \\
\hline 1907 & & & $1.391 .95^{3}$ & $2167.71^{2}$ & 3 559.72 & 5060.90 \\
\hline 1908 & & & $522.52^{3}$ & $880.38^{2}$ & 1402.90 & 2902.90 \\
\hline 1910 & & & $1330.81^{3}$ & & 1330.81 & 1330.81 \\
\hline 1911 & & & $1536.32^{3}$ & & 1536.32 & 1574.07 \\
\hline
\end{tabular}

\footnotetext{
* Compárese con junio de 1892, en el que las deudas son mucho mayores.

AGN-FRyA, Caja 80.

'Incluye la deuda de alquiladós: $\$ 663.27$.

2 Incluye arrendatarios, medieros y tercieros.

3 Incluye sirvientes corrientes y cesantes.

Fuente: La misma del Cuadro General... del anterior capitulo.
} 
En síntesis, el trabajo forzoso a través del endeudamiento fue una característica de Mezquite durante el porfiriato. Sin embargo, a partir de la segunda mitad de la década de los noventa, los dependientes se transformaron en acreedores de la hacienda y la deuda se concentró en los sirvientes, tanto permanentes como alquilados. Estos últimos, que no recibían ración de maíz, fueron controlados por la tienda de raya vía el endeudamiento. Así, el endeudamiento como mecanismo de coacción del trabajo agricola tuvo en Mezquite características diferentes de acuerdo a la estratificación social.

\section{ELSALARIO}

Uno de los primeros intentos por sistematizar el estudio de los salarios durante el porfiriato, por desgracia no continuado, se debe, como se dijo inicialmente, a Fernando Rosenzweig. ${ }^{22}$ Para este autor, los salarios agricolas del país, debido a la influencia que ejerció sobre ellos el crecimiento general de la economia, aumentaron aunque débilmente hasta 1898; en el último decenio del porfiriato disminuirian sensiblemente.

\begin{tabular}{|c|c|c|c|c|}
\hline \multicolumn{5}{|c|}{$\begin{array}{l}\text { CUADRO } 7 \\
\text { Créditos pasivos de Mezquite, } 1877-1911 \\
\text { (Pesos) }\end{array}$} \\
\hline Años & & Dependientes & Sirvientes & $\begin{array}{l}\text { Total de } \\
\text { créditos }\end{array}$ \\
\hline $\begin{array}{l}1877 \\
1878 \\
1880 \\
1887 \\
1888^{*} \\
1889 \\
1890 \\
1891 \\
1892 \\
1895 \\
1896 \\
1897 \\
1898 \\
1899 \\
1900 \\
1901 \\
1902 \\
1903 \\
1904 \\
1905 \\
1906 \\
1907 \\
1908 \\
1910 \\
1911\end{array}$ & . & $\begin{array}{rr} & \\
& \\
& \\
& \\
& \\
& \\
& \\
& 725.12 \\
& 720.53 \\
1 & 935.72 \\
2 & 645.16 \\
3 & 103.68 \\
3 & 103.40 \\
3 & 911.48 \\
2.415 .06 \\
\\
3.56 \\
642.67 \\
679.04 \\
19.72\end{array}$ & 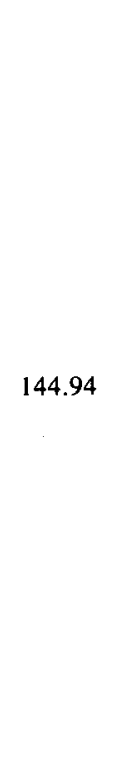 & $\begin{array}{rr}32 & 598.82 \\
52 & 455.03 \\
51 & 414.61 \\
46.564 .15 \\
58603.90 \\
60250.80 \\
85991.61 \\
108798.50 \\
93318.79 \\
20934.64 \\
34021.25 \\
20103.41 \\
865.47 \\
1935.72 \\
2645.16 \\
3103.18 \\
4682.99 \\
11231.28 \\
15123.96 \\
490.08 \\
1733.87 \\
679.04 \\
835.87 \\
. \quad\end{array}$ \\
\hline
\end{tabular}

* Los otros acreedores eran: Inés de León, Viadero y Cía., Muriedas y Cía., Fco. Camacho, Manuel Guerra, J. y M. Ibargüengoitia, Esteban Ortega, el Curato de Fresnillo y la Testamentaria de J. Ma. Flores.

Fuente: Ibid, Cuadro General.

s2 Fernando Rosenzweig, “El desarrollo...", op. cit., p. 446-454. 
Por desgracia, no existe información seriada para Mezquite sobre salarios. Los datos que poseo corresponden sólo a algunos años de fines del siglo pasado; aunque escasos, permiten ciertas comparaciones. Siguiendo la clasificación de los trabajadores propuesta, puede decirse lo siguiente: los salarios de los dependientes en general, en promedio mensual, fueron en 1893 de 25.92 pesos y de 27.90 incluyendo la ración de maíz; para 1895 su salario disminuyó a 23.20 pesos pero con la ración aumentó a 29.14; en 1897 el salario de los dependientes mismos fue de 25.18 pesos, aunque con la ración alcanzó los 30.70 pesos. Por lo tanto, los dependientes en general, si bien vieron disminuir su salario nominal en los años indicados, de hecho aumentaron si se consideran las raciones de maiz; es decir, las raciones fueron una forma de compensar los salarios de los dependientes (los principales, incluso, recibían ración de carne, la cual no se considera en los datos presentados).

El caso de los sirvientes permanentes es diferente: mantuvieron un salario promedio entre 1893-1897 de 4.90 pesos mensuales; sin embargo, el salario más la ración de maíz, por el contrario de los dependientes, disminuyó de 9.10 pesos mensuales en 1893 a 7.71 en 1895 y 7.91 en 1897. Por su parte, el jornal (en promedio mensual) de los sirvientes alquilados, que no recibían ración, siendo el más bajo de todos, permaneció sin grandes alteraciones en los años mencionados aunque con

\begin{tabular}{|c|c|c|c|c|c|c|c|}
\hline & & Tienda de & $\begin{array}{r}\text { CUA } \\
\text { raya en } 1 \\
(\mathrm{Pe}\end{array}$ & $\begin{array}{l}\text { DRO } 8 \\
\text { Vezquite, } 1 \\
\text { Sos) }\end{array}$ & $877-1911$ & & \\
\hline Años & $\begin{array}{l}\text { Valor de } \\
\text { efectos }\end{array}$ & $\begin{array}{l}\text { Deudas de } \\
\text { alquilados }\end{array}$ & $\begin{array}{c}\text { medieros y } \\
\text { tercieros }\end{array}$ & Arrendatarios & s. Sirvientes & Dependientas & Total \\
\hline $\begin{array}{l}1877 \\
1878 \\
1880 \\
1887 \\
1888 \\
1889 \\
1890 \\
1891 \\
1892 \\
1895 \\
1896 \\
1897 \\
1898 \\
1899 \\
1900 \\
1901 \\
1902 \\
1903 \\
1904 \\
1905 \\
1906 \\
1907 \\
1908\end{array}$ & $\begin{array}{ll}4 & 923.55 \\
3 & 683.87 \\
3 & 651.12 \\
5 & 667.21 \\
2 & 289.50 \\
3 & 561.81 \\
4 & 310.21 \\
1 & 946.79 \\
2 & 614.85 \\
2 & 880.66 \\
4 & 025.91 \\
5 & 311.20 \\
8 & 319.18\end{array}$ & $\begin{array}{r}301.57 \\
729.34 \\
1265.61 \\
224.88 \\
375.63 \\
876.97 \\
695.36 \\
976.01 \\
1760.27 \\
1231.18 \\
618.75 \\
-\quad 324.04 * \\
-406.45\end{array}$ & & & 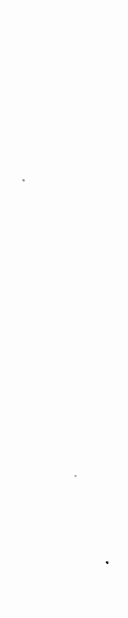 & 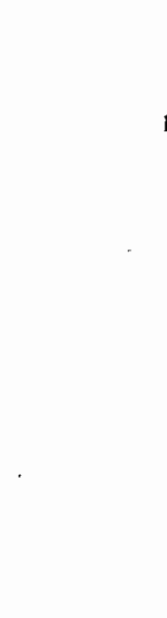 & $\begin{array}{r}5297.03 \\
6785.67 \\
4850.38 \\
7177.28 \\
16177.06 \\
6288.87 \\
425.19 \\
9990.43 \\
8951.77 \\
5225.12 \\
4413.21 \\
4916.73 \\
5892.09 \\
2665.13 \\
4438.78 \\
5005.57 \\
2922.80 \\
4375.12 \\
4111.84 \\
4644.66 \\
4744.00 \\
7932.73\end{array}$ \\
\hline $\begin{array}{l}1910 \\
1911\end{array}$ & $\begin{array}{l}1313.51 \\
1136.06\end{array}$ & $\begin{array}{r}357.59 \\
3181.75\end{array}$ & 1278.77 & 506.78 & 106.70 & 70.84 & $\begin{array}{l}3634.19 \\
4466.12\end{array}$ \\
\hline
\end{tabular}

* El signo de menos indica saldo a favor de alquilados.

Fuente: Ibid, Cuadro General. 
tendencia a decrecer (cuadro 9). En síntesis, el salario nominal (incluyendo la ración) entre 1893-97 de los trabajadores de Mezquite tuvo un comportamiento diferenciado: el de los dependientes aumentó en un $10 \%$ debido principalmente a la ración; el de los sirvientes permanentes, por el contrario, disminuyó en un $15 \%$ por la disminución de la ración; el jornal de los alquilados, que no recibían ración, se mantuvo en el nivel más bajo de todos.

Los datos anteriores se refieren al salario nominal. Para conocer el poder de compra de los trabajadores de Mezquite he elaborado una "canasta básica" compuesta por 15 productos más o menos básicos, 9 de consumo no duradero o consumo final (maiz, frijol, chile, arroz, sal, azúcar, garbanzo, lenteja y café) y 6 de consumo durable o intermedio (manta, dril, rebozo, chaqueta, botas y sombrero), a partir de los inventarios de la tienda de raya. El procedimiento es un poco arbitrario pero permite una aproximación efectiva al salario real para los años de 1894 y 1897. Los resultados son interesantes: el índice de precios de los bienes de consumo no duradero fue de 254 ; el de los bienes de consumo durable de 157 , lo cual quiere decir que el precio de los alimentos fue el más inflacionario. El indice general de precios fue de 215 , es decir, el índice inflacionario fue de $115 \%$ entre los años de 1894 y 1897 (cuadro 10). Ello contrasta con el comportamiento de los salarios nominales de los trabajadores de la hacienda: mientras que el de los dependientes aumentaba apenas en un $10 \%$, el de los sirvientes permanentes incluso disminuia en un $15 \%$. Por lo tanto, el salario real de los trabajadores de Mezquite, en especial el de los sirvientes, disminuyó sensiblemente años antes que el promedio nacional, es decir, desde la última década del siglo pasado.

F. Katz afirmó que los hacendados norteños, para conservar a sus trabajadores, tenían que ofrecer un salario creciente. ${ }^{53}$ Por los datos presentados sobre Mezquite, el comentario de Katz es válido sólo para los dependientes. Por otra parte, según este mismo autor, en el norte del país, donde predominaba la ganadería durante el porfiriato, el número de trabajadores permanentes era mayor que en otras regiones del país. ${ }^{54}$ En términos generales, para los mismos años de 1893-97, el comentario es aplicable para Mezquite (cuadro 11). Aunque puede observarse un incremento del porcentaje de los sirvientes alquilados: de $14.4 \%$ en 1893 a $31.3 \%$ en 1897 . Aqui es importante aclarar que, a diferencia de la opinión de Juan Felipe Leal y de Mario Huacuja sobre una hacienda del centro del país, el incremento de los sirvientes alquilados en Mezquite no significó un ascenso del trabajo libre y asalariado sino, por el contrario, una ampliación del trabajo forzoso. ${ }^{55}$ Destaca también de los datos sobre el número de trabajadores la disminución del total. Esto tiene que ver desde luego con el periodo crítico de Mezquite, al que ya sé hizo mención, el cual provocó desempleo; el dato es también explicable por la fuerte tendencia de los sirvientes a emigrar. La pregunta obligada es sobre esta tendencia. La respuesta es múltiple: por la atracción que ejercían los centros mineros de más al norte, así como los

s.3 F. Katz, op. cit.

it Ibid.

is AGN-FRyA, Cajas 110 y 210 . Juan Felipe Leal y Mario Huacuja, op. cit., p. 72-73. Para los autores del predominio del trabajo de los alquilados representó el paso de la renta de trabajo a la plusvalia absoluta. Olvidan una cuestión fundamental: el endeudamiento de los alquilados. 


\begin{tabular}{|c|c|c|c|c|c|c|c|c|}
\hline 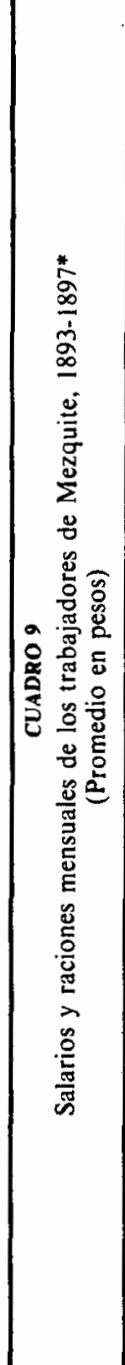 & 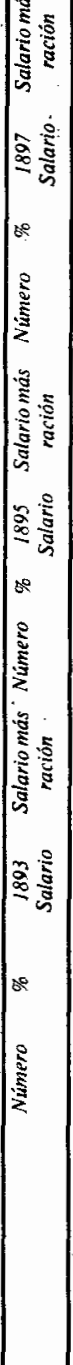 & 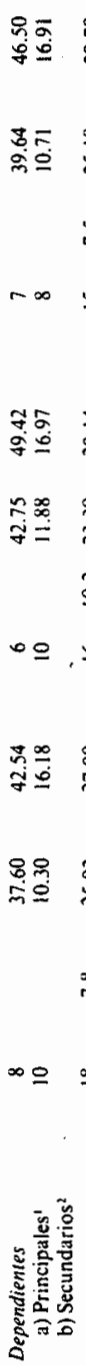 & 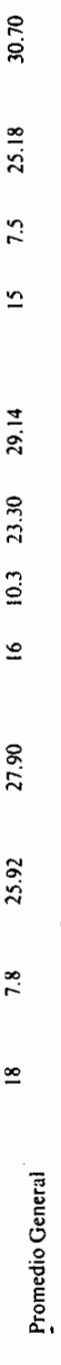 & 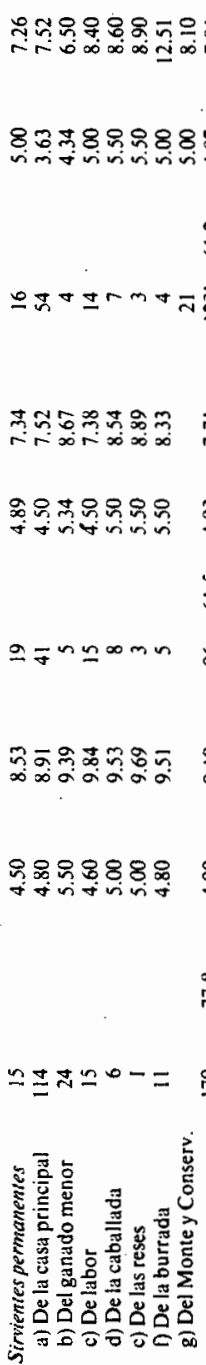 & 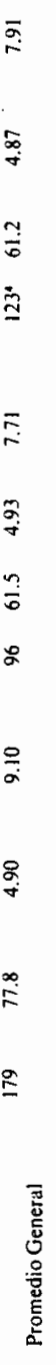 & 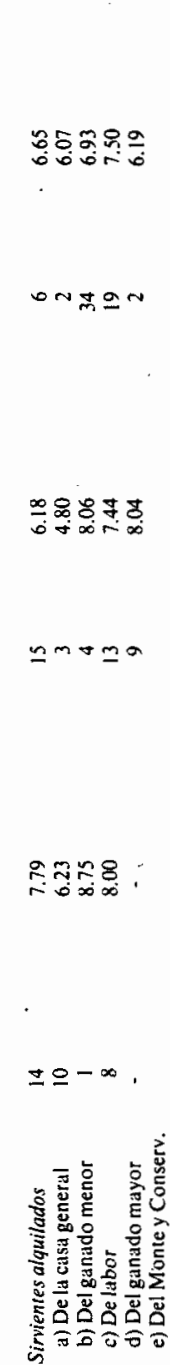 & 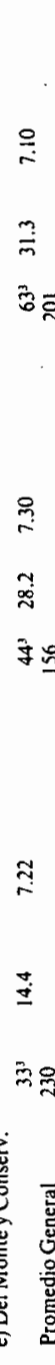 & 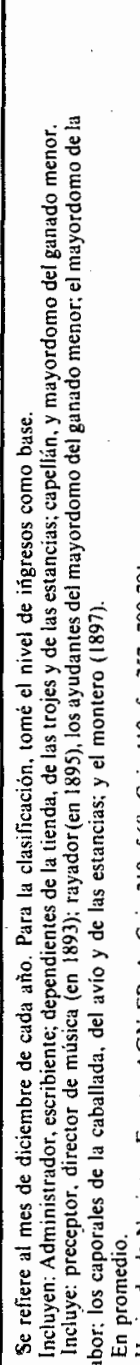 \\
\hline
\end{tabular}




\section{CUADRO 10}

Índice de precios para los productos de la tienda de raya en Mezquite, 1894-1897*

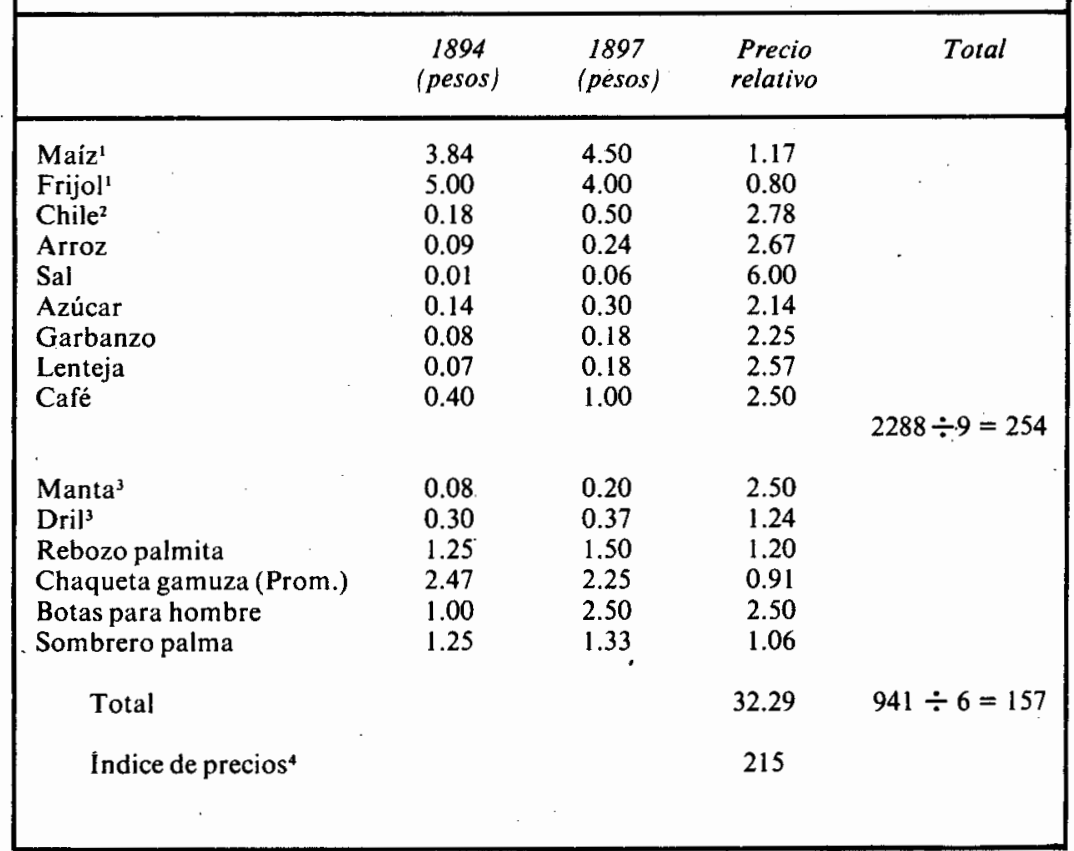

* Para el mes de diciembre de cada año.

1 Para 1894 el precio es por fanega, para 1897 por hectolitro.

2 Para 1894 el precio es por libra, para 1897 por kilo. Los demás están dados en libras.

3 Para 1894 el precio es por vara, para 1897 por metro. Los restantes, precio por unidad.

${ }_{4}$ El indice no está ponderado, porque no existen datos del consumo.

Fuente: AGN-FRyA, Caja 210, fs. 71-79; Caja 110, exp. 1, fs. 521-524.

\section{CUADRO 11}

Participación porcentual de los trabajadores en Mezquite, 1893-1897

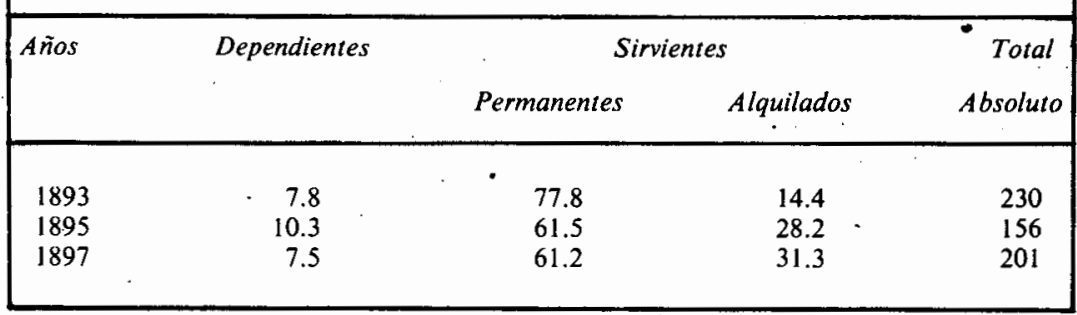

Fuente: Ibid., Cuadro 9. 
Estados Unidos; ${ }^{56}$ más concretamente, por el bajo nivel de salario y su correlativo, el endeudamiento como mecanismo de coacción. En otras palabras, por la reducción drástica del nivel de vida de los sirvientes, lo cual debió orillarlos a la búsqueda de mejores condiciones.'

Una de las cuestiones más complejas de la investigación sobre las haciendas porfirianas es precisar cómo las diferentes condiciones sociales, afectaron la conducta de cada grupo en la revolución de $1910 . .^{57}$ En el norte del país, de acuerdo con Katz, los ejércitos revolucionarios tuvieron una gran heterogeneidad; la clase media rural (lo que aquí he considerado como dependientes) definieron sin embargo el movimiento norteño. No dudo que en Mezquite los dependientes desempleados se lanzaran a la revolución; sólo puedo agregar que los sirvientes, para entonces, no tenían ya escapatoria, ni fugándose más al norte del pais ni "p'al otro lado".

s6 Moisés González Navarro, "El trabajo forzoso en México", Historia Mexicana, vol. XVII: 4.

${ }^{57}$ F. Katz, op. cit., p. 53. 